\title{
Comparative efficacy of long-acting bronchodilators for COPD - a network meta-analysis
}

Shannon Cope ${ }^{1}$, James F Donohue2, Jeroen P Jansen ${ }^{3}$, Matthias Kraemer ${ }^{4}$, Gorana Capkun-Niggli ${ }^{4}$, Michael Baldwin ${ }^{5}$, Felicity Buckley ${ }^{3}$, Alexandra Ellis ${ }^{3}$ and Paul Jones ${ }^{6 *}$

\begin{abstract}
Background: Clinicians are faced with an increasingly difficult choice regarding the optimal bronchodilator for patients with chronic obstructive pulmonary disease (COPD) given the number of new treatments. The objective of this study is to evaluate the comparative efficacy of indacaterol 75/150/300 $\mu \mathrm{g}$ once daily (OD), glycopyrronium

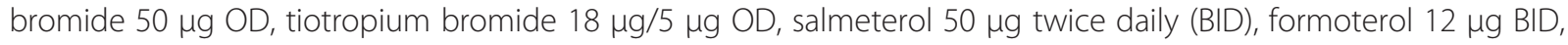
and placebo for moderate to severe COPD.

Methods: Forty randomized controlled trials were combined in a Bayesian network meta-analysis. Outcomes of interest were trough and post-dose forced expiratory volume in 1 second $\left(\mathrm{FEV}_{1}\right)$, St. George's Respiratory Questionnaire (SGRQ) score and responders ( $\geq 4$ points), and Transition Dyspnea Index (TDI) score and responders $(\geq 1$ point) at 6 months.

Results: Indacaterol was associated with a higher trough $\mathrm{FEV}_{1}$ than other active treatments (difference for indacaterol $150 \mu \mathrm{g}$ and $300 \mu \mathrm{g}$ versus placebo: $152 \mathrm{~mL}$ (95\% credible interval (Crl): 126, 179); $160 \mathrm{~mL}$ (95\% Crl: $133,187)$ ) and the greatest improvement in SGRQ score (difference for indacaterol $150 \mu \mathrm{g}$ and $300 \mu \mathrm{g}$ versus placebo: -3.9 (95\% Crl -5.2, -2.6); -3.6 (95\% Crl -4.8, -2.3)). Glycopyrronium and tiotropium $18 \mu \mathrm{g}$ resulted in the next best estimates for both outcomes with minor differences (difference for glycopyrronium versus tiotropium for trough $\mathrm{FEV}_{1}$ and SGRQ: $18 \mathrm{~mL}$ (95\% Crl: -16, 51); - 0.55 (95\% Crl: -2.04, 0.92).
\end{abstract}

Conclusion: In terms of trough $\mathrm{FEV}_{1}$ and $\mathrm{SGRQ}$ score indacaterol, glycopyrronium, and tiotropium are expected to be the most effective bronchodilators.

Keywords: COPD, Bronchodilator, Systematic review, Meta-analysis, Mixed treatment comparison

\section{Background}

Patients with chronic obstructive pulmonary disease (COPD) experience airway obstruction, involving reduced lung function and health-related quality of life due to symptoms such as breathlessness and exacerbations [1]. Since COPD is a progressive disease, the main objective of treatment is to improve lung function, prevent and control symptoms, and ultimately to improve health status. Bronchodilator medications are central to

\footnotetext{
* Correspondence: pjones@sgul.ac.uk

${ }^{6}$ Division of Clinical Science, St George's University of London, London SW17 ORE, UK

Full list of author information is available at the end of the article
}

symptom management in COPD, with long-acting preparations preferred over short-acting ones [1].

The classes of inhaled long-acting bronchodilators available for COPD are long-acting $\beta 2$-agonists (LABAs) (i.e. indacaterol $75 \mu \mathrm{g}, 150 \mu \mathrm{g}$ or 300 once daily (OD), salmeterol $50 \mu \mathrm{g}$ twice daily (BID), or formoterol $12 \mu \mathrm{g}$ (BID) and long-acting muscarinic antagonists (LAMAs, also called anticholinergic bronchodilators) (i.e. tiotropium bromide $18 \mu \mathrm{g}$ or $5 \mu \mathrm{g}$ OD). Recently two more LAMAs, aclidinium bromide $400 \mathrm{mg}$ BID and glycopyrronium bromide $44 \mu \mathrm{g}$ OD were recently approved by the European Medicines Agency and the Food and Drug Administration.

\section{Biomed Central}

(c) 2013 Cope et al.; licensee BioMed Central Ltd. This is an open access article distributed under the terms of the Creative Commons Attribution License (http://creativecommons.org/licenses/by/2.0), which permits unrestricted use, distribution, and reproduction in any medium, provided the original work is properly cited. 
Given the number of the alternative long-acting treatments available for COPD, clinicians are faced with an increasingly challenging choice regarding the optimal treatment. Since there is no head-to-head randomized controlled trial (RCT) that evaluates all the different monotherapies available, and it is unlikely that such a trial will ever be performed (given the increasing number of options available), a comprehensive systematic review and network meta-analysis is of interest to synthesize the RCT evidence. The objective of the current analysis was to evaluate the comparative efficacy of long-acting bronchodilators in patients with moderate to severe COPD in terms of lung function, health status, and dyspnoea. Approved bronchodilators or those for which data was available at the time of the literature search were included: indacaterol 75/150/ $300 \mu \mathrm{g}$ OD, salmeterol $50 \mu \mathrm{g}$ BID, formoterol $12 \mu \mathrm{g}$ BID, tiotropium bromide $18 \mu \mathrm{g}$ or $5 \mu \mathrm{g}$ OD, aclidinium bromide $200 \mu \mathrm{g}$ OD and glycopyrronium bromide $50 \mu \mathrm{g}$ OD. No evidence for the approved dose of aclidinium bromide was available at the time of the search, therefore results for aclidinium bromide $200 \mu \mathrm{g}$ OD were included in the analysis but are not presented given that this dose has not been approved.

\section{Methodology}

\section{Identification and selection of articles}

A systematic literature search was performed to identify RCTs evaluating the efficacy of the long-acting monotherapies for COPD. MEDLINE ${ }^{\circ}$ and EMBASE $^{\circ}$

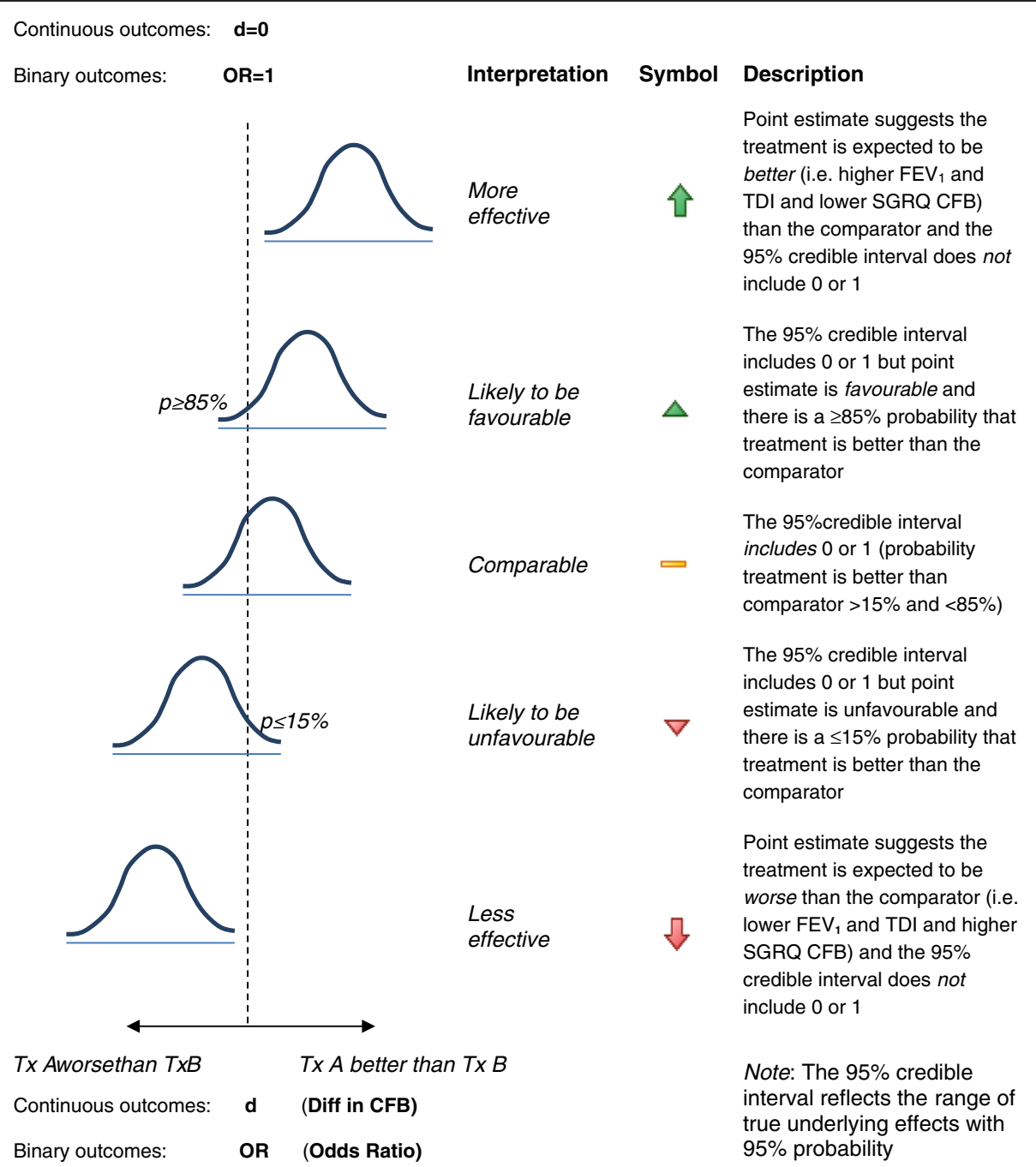

Figure 1 Interpretation of the relative treatment effects resulting from the network meta-analysis for continuous and binary outcomes. $\mathrm{CFB}=$ Change from baseline; $\mathrm{D}=$ difference in $\mathrm{CFB}$; $\mathrm{FEV}_{1}=$ Forced expiratory volume; $\mathrm{OR}=$ odds ratio; $\mathrm{SGRQ}=\mathrm{St}$. George's Respiratory Questionnaire;

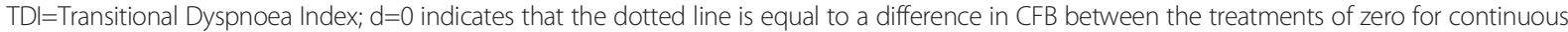
endpoints (i.e. no difference between treatments); $\mathrm{OR}=1$ indicates that the dotted line is equal to an odds ratio of one for binary endpoints (i.e. no difference between treatments). 


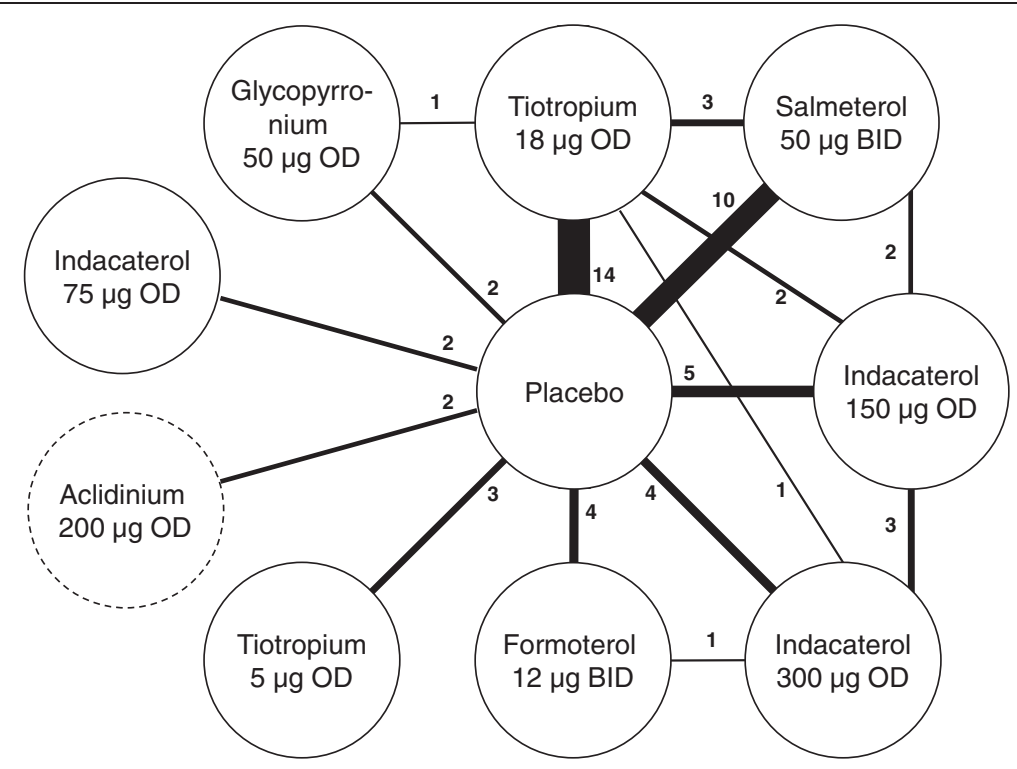

Figure 2 Network of RCTs included in the network meta-analysis. Note: The thickness of the lines corresponds to the number of RCTs available for each treatment comparison; Two RCTs comparing aclidinium $200 \mu \mathrm{g}$ OD to placebo were included in the network of evidence but results were not presented since this dose has not been approved.

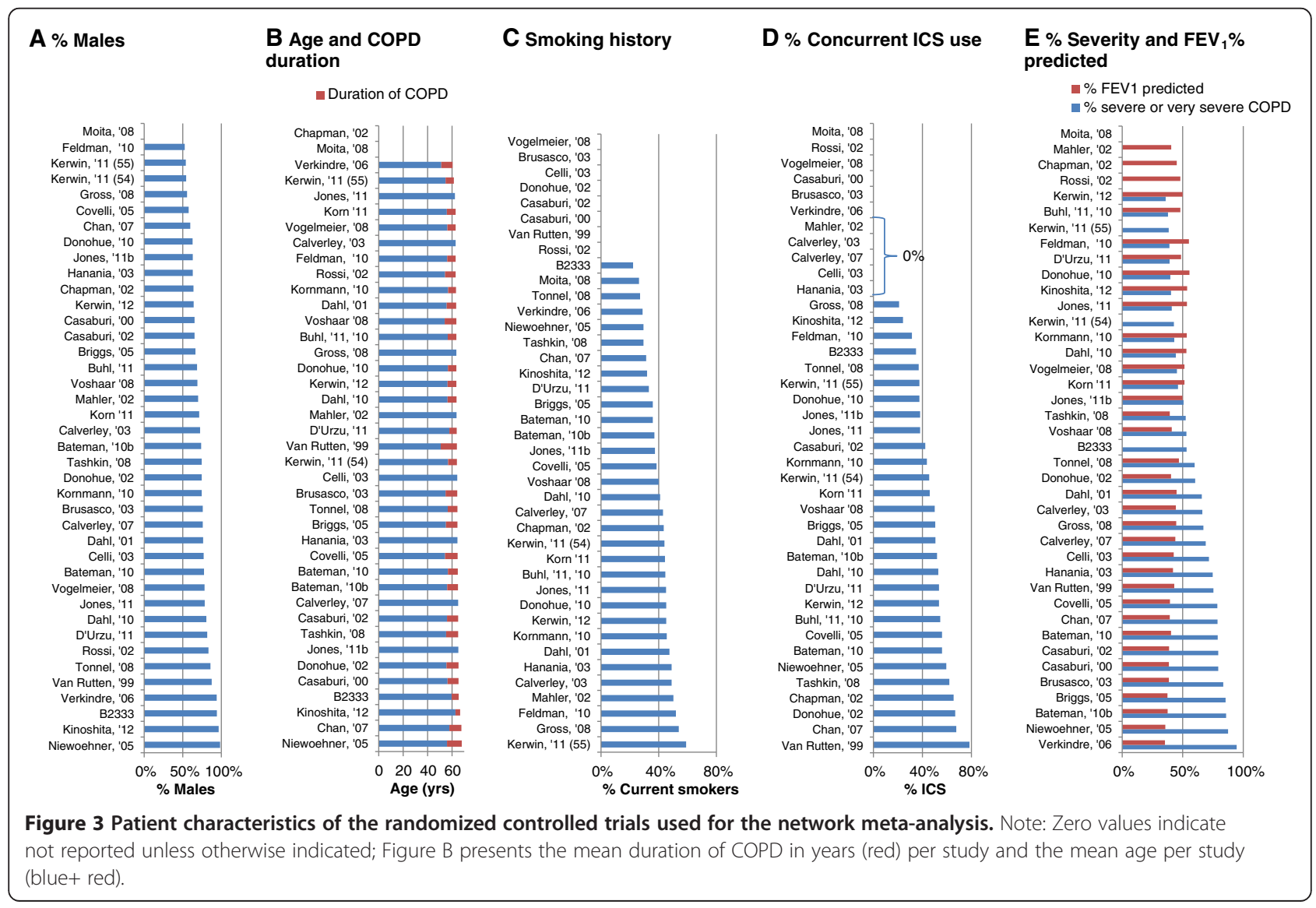


A) Trough FEV $_{1}$ at 6 months

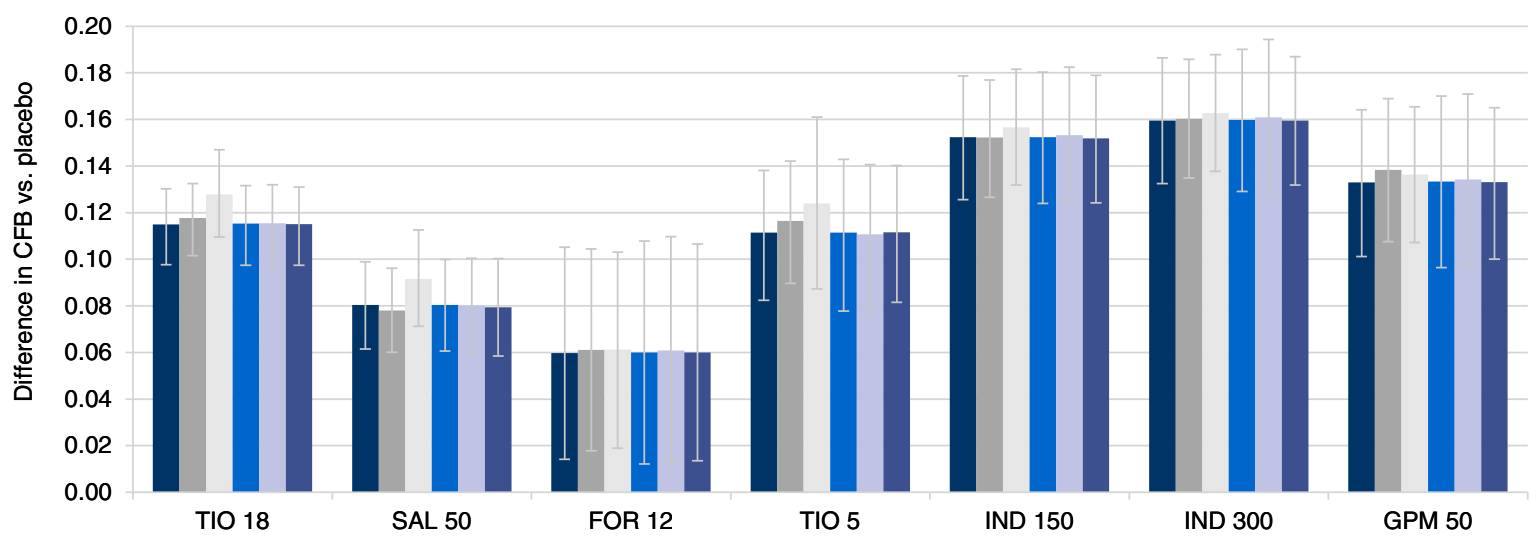

B) Post-dose FEV 1 at 6 months

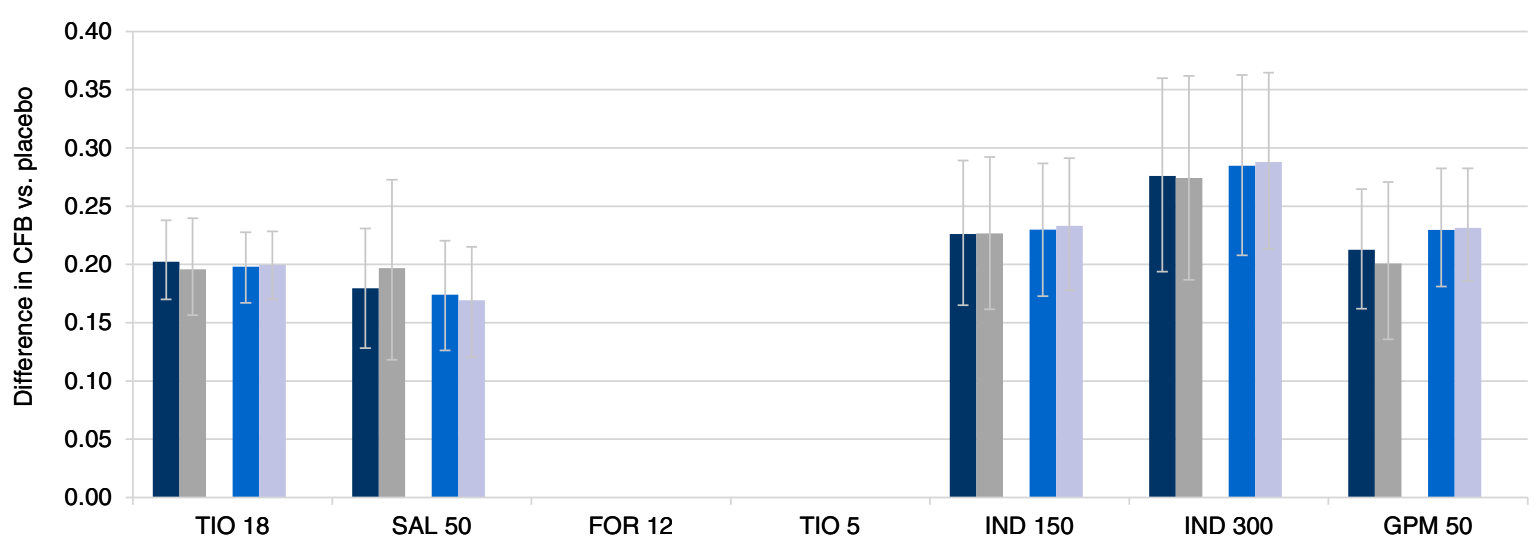

Analysis Type Description

\#1 $\quad \begin{array}{ll}\text { Base } & \text { All evidence analysis (without covariates) }\end{array}$
\#2 Scenario Base case adjusted for proportion of patients receiving ICS at analysis baseline in each RCT
\#3 Scenario Base case excluding RCTs allowing LABAs or LAMAs during analysis the trial, beyond study treatments

\#4 Scenario Base case adjusted for proportion patients in each RCT with analysis severe or very severe COPD (based on GOLD criteria)

\#5 Scenario Base case adjusted for RCTs with a high proportion of patients analysis with severe or very severe COPD $(\geq 60 \%)$

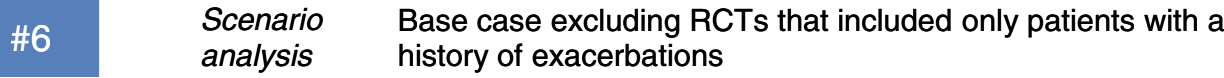


(See figure on previous page.)

Figure 4 Trough and post-dose FEV 1 network meta-analysis results at 6 months: Difference in change from baseline (CFB) versus placebo. Bars represent 95\% Credible Interval; $C F B=$ Change from baseline; FEV $1=$ Forced expiratory volume; FOR $12=$ Formoterol $12 \mu \mathrm{g}$ twice daily (BID); GPM $50=$ Glycopyrronium $50 \mu \mathrm{g}$ once daily (OD); IND $150=$ Indacaterol $150 \mu \mathrm{g}$ OD; IND $300=$ Indacaterol $300 \mu \mathrm{mg}$ OD; SAL 50=Salmeterol $50 \mu \mathrm{g} \mathrm{BID} ; \mathrm{TIO} 5=$ Tiotropium $5 \mu \mathrm{g}$ OD; TIO $18=$ Tiotropium $18 \mu \mathrm{g} \mathrm{OD}$.

databases were searched simultaneously for the period of 1989 to July 2011 and the Cochrane Library was also searched. Search terms included a combination of freetext and thesaurus terms relevant to COPD, the treatments of interest, and RCTs (see Additional file 1). Cope et al. 2012 searched the literature from 19892010 and this was updated for $2010-2011$ for the treatments of interest. The relevance of each citation identified was based on title and abstract (or full-text article) according to predefined selection criteria:

Population: Adults with COPD;

Interventions: Indacaterol 75/150/300 $\mu \mathrm{g} \mathrm{OD}$, tiotropium 5/18 $\mu \mathrm{g}$ OD, salmeterol $50 \mu \mathrm{g}$ BID, formoterol $12 \mu \mathrm{g}$ BID, aclidinium 200/400 $\mu \mathrm{g}$ OD, and glycopyrronium $50 \mu \mathrm{g}$ OD;

Comparators: Any of the interventions evaluated as monotherapy or placebo;

Outcomes: Trough forced expiratory volume in $1 \mathrm{sec}-$ ond $\left(\mathrm{FEV}_{1}\right)$, post-dose $\mathrm{FEV}_{1}$ (2 hours after dosing), St. George's Respiratory Questionnaire (SGRQ) total score and proportion of patients with an improvement of at least 4 units in SGRQ total score ("SGRQ Responders" [2]), Transition Dyspnoea Index (TDI) total score and proportion of patients with an improvement of at least 1 unit in TDI score ("TDI Responders" [3]), proportion of patients with an exacerbation and exacerbation rate;

Study Design: RCTs.

In addition to the studies identified in the systematic review, clinical trial reports were provided by Novartis for trials evaluating indacaterol and glycopyrronium, all of which had been published at the time of the search except for the trial B2333 (NCT00792805) [4-14].

\section{Outcomes of interest}

The outcomes of interest included trough $\mathrm{FEV}_{1}$, post-dose $\mathrm{FEV}_{1}$, SGRQ total score, SGRQ responders, TDI total score, and TDI responders. Change from baseline was evaluated for all continuous outcomes, with the exception of TDI which was evaluated at follow-up. The current analysis focuses on results at 6 months (discussed in the following), although endpoints were also analyzed at 12 weeks (see online Additional file 1). Exacerbation outcomes will be evaluated in separate manuscript in order to account for differences in definitions.

\section{Data extraction}

Information related to the study and patient characteristics was extracted for the included studies, which allowed for a comprehensive assessment of the similarities and differences across the trials. For each outcome the mean results and the associated uncertainty (i.e. standard error) were extracted where sufficient information was available within a two week range for each time point of interest (i.e. between 22-26 weeks for 6 month time point). If necessary, the software DigitizIt version 1.5.8 was used to extract data from graphs presented in the publications.

\section{Network meta-analysis}

Bayesian network meta-analysis (NMA) models were used [15-18] to simultaneously synthesize the results of the included studies for each outcome of interest.

NMAs within the Bayesian framework involve data, a likelihood distribution, a model with parameters, and prior distributions [19]. The model relates the data from the individual studies to basic parameters reflecting the (pooled) treatment effect of each intervention relative to placebo as the overall reference treatment. Based on these basic parameters, the relative efficacy between each of the interventions was obtained. For the continuous outcomes a normal likelihood distribution was used and for the binary outcomes a binomial likelihood was used $[16,17,20,21]$. For each analysis, both fixed and random effects models were evaluated. With a NMA, randomization only holds within a trial and not across trials. Consequently, there is the risk that patients who were studied in different comparisons are not similar, which may lead to consistency violations. In order to minimize confounding bias, analyses with a constant treatment by covariate interaction were evaluated [22] or analyses were performed excluding specific trials to assess the impact of potential treatment effect modifiers. Potential treatment effect modifiers were identified a priori as concomitant treatments, COPD severity, smoking status, age, and sex. Separate analyses were performed to evaluate the potential treatment effect modifiers given the limited number of studies included in each analysis. Noninformative prior distributions for the model parameters were implemented to avoid influencing the results of the analysis based on the prior beliefs.

For each model with and without covariates, both fixed and random effects models were tested. The deviance information criterion was used to compare the models, which provides a measure of model fit that penalizes model complexity accordingly [23]. The random effects model was selected unless there was sufficient evidence to suggest the fit of the fixed effect model was 
A) SGRQ total score at 6 months

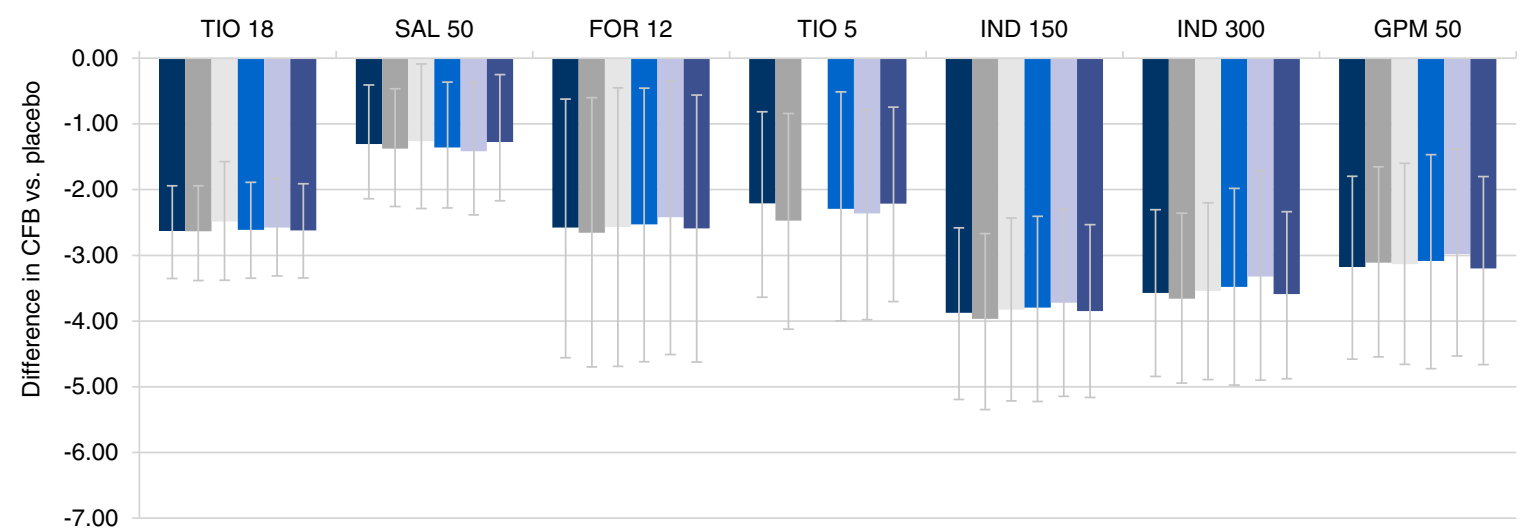

B) SGRQ responders at 6 months

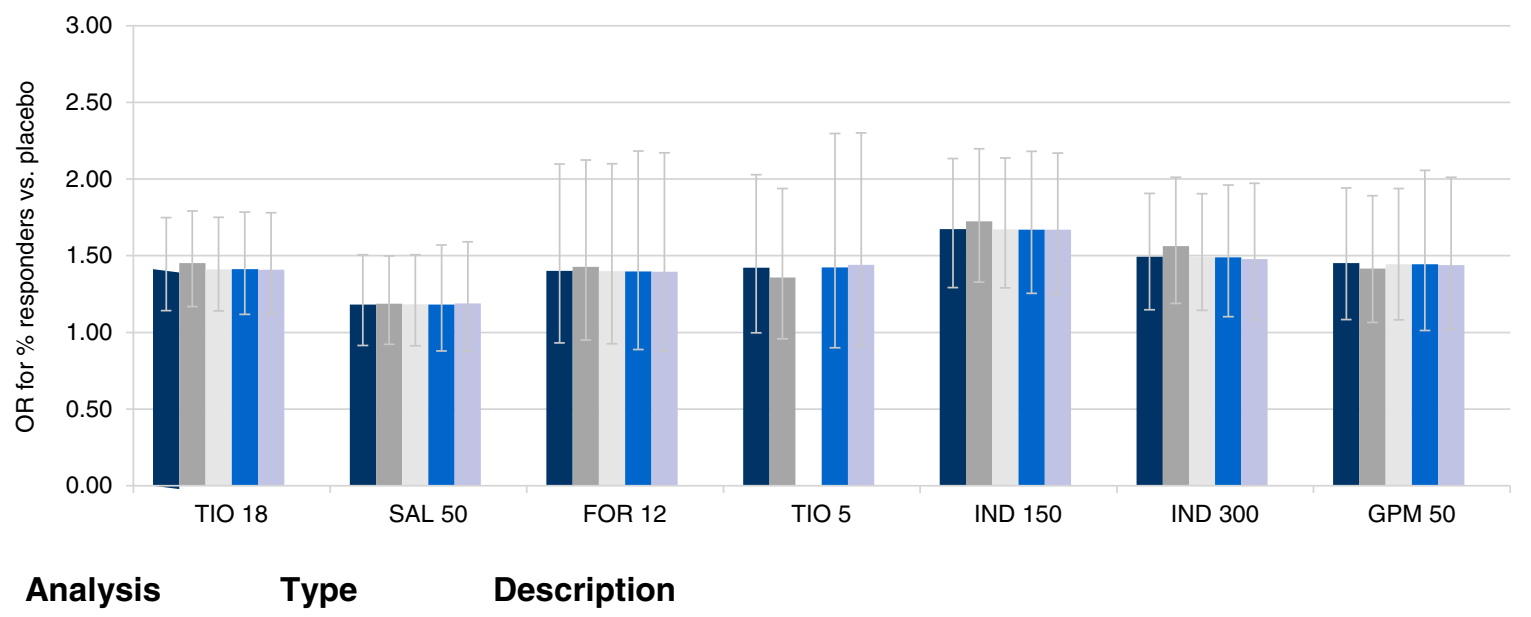

\section{$\# 1$}

\section{\#2}

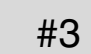

\section{\#4}

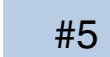

\#6
Base case

Scenario analysis

Scenario analysis

Scenario analysis

Scenario analysis

Scenario analysis
All evidence analysis (without covariates)

Base case adjusted for proportion of patients receiving ICS at baseline in each RCT

Base case excluding RCTs allowing LABAs or LAMAs during the trial, beyond study treatments

Base case adjusted for proportion patients in each RCT with severe or very severe COPD (based on GOLD criteria)

Base case adjusted for RCTs with a high proportion of patients with severe or very severe COPD $(\geq 60 \%)$

Base case excluding RCTs that included only patients with a history of exacerbations 
(See figure on previous page.)

Figure 5 SGRQ network meta-analysis results at 6 months: Difference in change from baseline (CFB) or odds ratio (OR) for responders versus placebo. Bars represent 95\% Credible Interval; CFB = Change from baseline; FOR $12=$ Formoterol $12 \mu \mathrm{g}$ twice daily (BID); GPM $50=$ Glycopyrronium $50 \mu \mathrm{g}$ once daily (OD); IND $150=$ Indacaterol $150 \mu \mathrm{g}$ OD; IND $300=$ Indacaterol $300 \mu \mathrm{g}$ OD; OR= Odds ratio; $\mathrm{SAL} 50=$ Salmeterol $50 \mu \mathrm{g} \mathrm{BID;} \mathrm{SGRQ}=$ St. George's Respiratory Questionnaire; TIO $5=$ Tiotropium $5 \mu \mathrm{g}$ OD; TIO $18=$ Tiotropium $18 \mu \mathrm{g}$ OD.

better. The analyses were performed using WinBUGS 1.4.1 statistical software [24].

The results of the NMA are presented in terms of 'point estimates' for the relative treatment effects and the $95 \%$ credible intervals $(95 \% \mathrm{CrI})$. The probability that each treatment is best is also presented which is calculated based on the proportion of Markov chain Monte Carlo cycles in which a specific treatment ranks first out of the total (where the ranking is based on the treatment effect size) [25]. Figure 1 outlines the interpretation of the results for continuous and binary outcomes, which utilizes the probability that one treatment is better than another (i.e. proportion of cycles in which specific treatment estimate is better than the comparator).

\section{Results \\ Evidence base}

The systematic review identified 51 RCTs, of which 40 RCTs were included in the NMA (See Additional file 1: Figure S1 in the online supplement) [4-14,26-52]. Eleven RCTs that did not report the outcomes of interest within the time frames of interest were excluded [53-63] (see flow chart in Additional file 1: Figure S1). Figure 2 illustrates the network of RCTs included in the NMA and the key study characteristics are presented in the online supplement (see Additional file 1: Table S1).

All studies were parallel placebo-controlled multi-center RCTs, with the exception of three RCTs that compared active treatments only $[5,13,28]$. All trials were doubleblind, although three RCTs evaluated open-label tiotropium [7,11,51]. The RCTs were generally considered of good quality, but the method of randomization and concealment of treatment allocation were not always well reported.

The study designs were mostly similar with some differences in terms of the study location and background medications. The studies were predominantly European and North American, although two trials were based in Asia $[4,12]$ and some trials included study centers in South America, Africa, and Asia [6,7,14]. Most RCTs allowed patients to receive a concomitant ICS, whereas some RCTs allowed the continued use of LABAs $[26,35,37,44,45,48]$ or LAMAs [30,36].

The enrolled patients had a COPD diagnosis, were 40 years of age or older and were current or ex-smokers with a smoking history of at least 10 years. Selected RCTs included patients with a smoking history of at least 15 years [34] or 20 years [6,7,9,12,14,41,43]. Generally, patients were required to have an $\mathrm{FEV}_{1} / \mathrm{FVC}$ of less than or equal to 0.70 and an $\mathrm{FEV}_{1}$ percent predicted often between 30 and $80 \%$, although this range varied across the studies (see Additional file 1: Table S1). Exacerbation history was reported in only five of the RCTs $[8,11,31,36,42]$, and two studies specified inclusion criteria with respect to exacerbations history, requiring at least one exacerbation over the prior one to two years [35] or one exacerbation per year over the prior three years [30]. Figure 3 illustrates the variation in the RCTs in terms of the proportion of males (range: 52-99\%), average age (range: 60-68 years), duration of COPD (range: 3.8-13.1 years), proportion of current smokers (range: 22-59\%), proportion receiving ICS during the trial (range: 0-78\%), and the proportion with severe or very severe COPD (range: 36-95\%) as reported based on the GOLD criteria or calculated as function of the $\mathrm{FEV}_{1} \%$ predicted. Overall, differences were most apparent in terms of ICS use and severity.

\section{Network meta-analysis}

The RCTs were synthesized with a network metaanalysis. The individual study results are presented in an online supplement (See Additional file 1: Tables S2-7). In the base case analysis all RCTs were included without covariates. Scenario analyses were performed to explore the impact of differences identified in terms of concomitant ICS use, concomitant LABAs or LAMAs, COPD severity, and exacerbation history that were considered most likely to cause bias. These covariates were selected based on the extent of the variation across the RCTs and any evidence regarding treatment effect modifiers in the individual studies. Initially the results for the base case analysis at 6 months are presented by outcome. Figures 4 , 5 , and 6 present the base case and scenario analyses at 6 months, which illustrate the results of the NMA for each treatment versus placebo in terms of lung function, health status, and dyspnoea, respectively. The last section summarizes the impact of the scenario analyses across the outcomes.

Trough and post-dose forced expiratory volume in 1 second In terms of change from baseline (CFB) in lung function, results from the base case analysis suggest that there is $64 \%$ probability that indacaterol $300 \mu \mathrm{g}$ provides the greatest improvement in trough $\mathrm{FEV}_{1}$ and an $83 \%$ probability of the greatest effect in post-dose $\mathrm{FEV}_{1}$. Indacaterol $150 \mu \mathrm{g}(29 \% ; 10 \%)$ and glycopyrronium $(6 \% ; 6 \%)$ are less likely to provide the greatest improvement in these 
A) TDI total score at 6 months

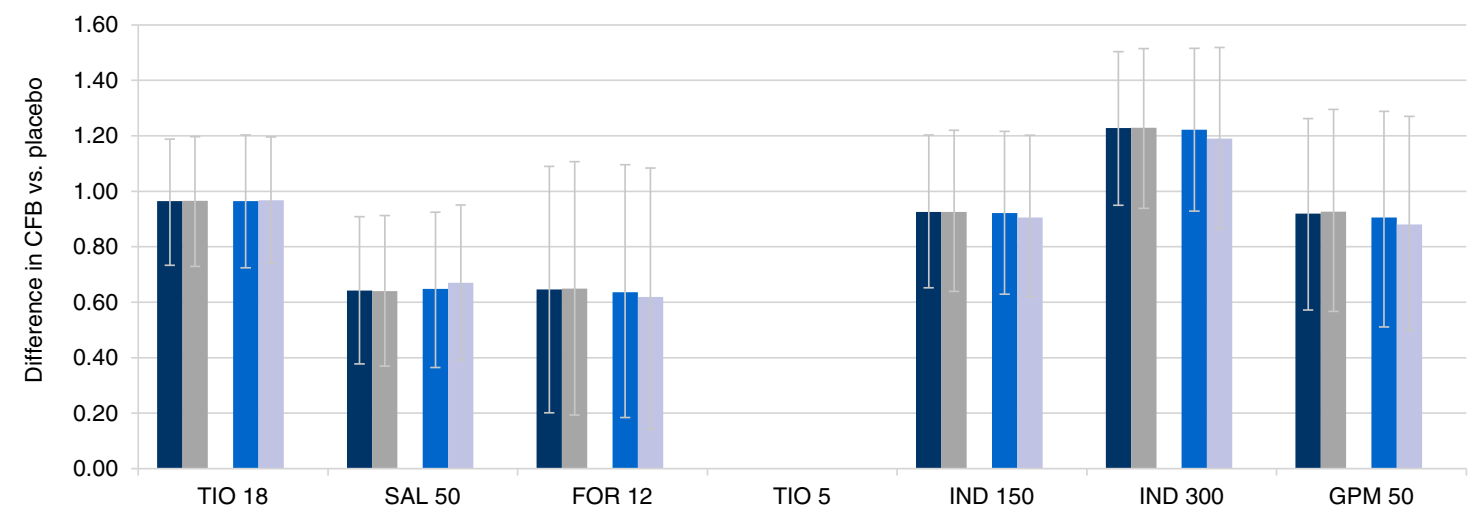

B) TDI responders at 6 months

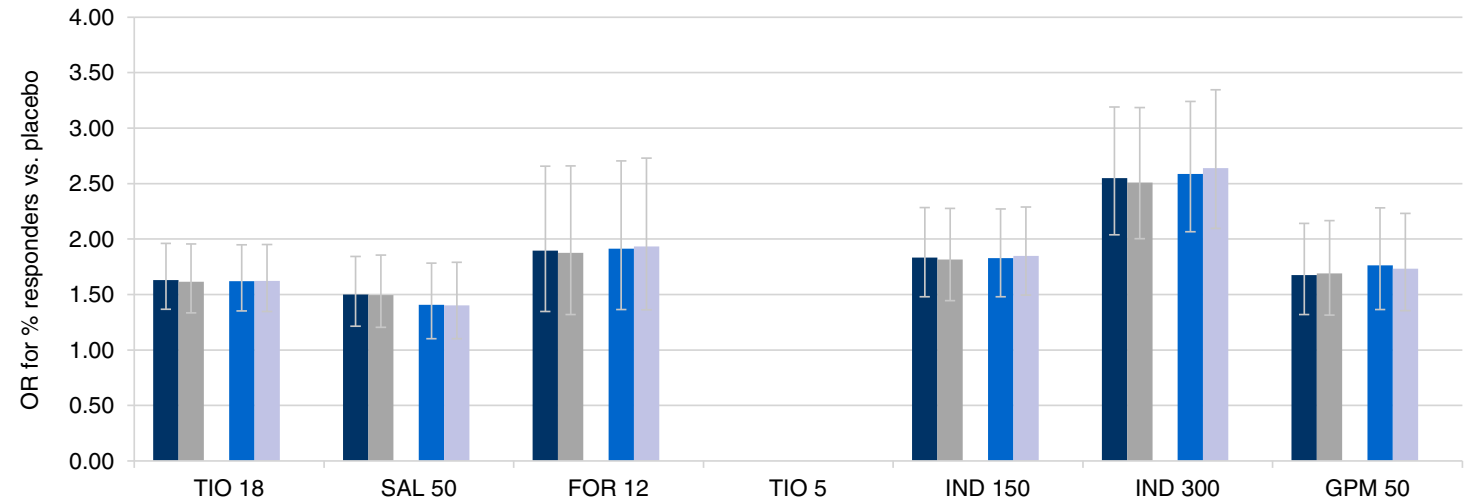
Analysis
Type
Description

\begin{tabular}{c|l} 
\#1 & $\begin{array}{l}\text { Base } \\
\text { case }\end{array}$ \\
\hline \#2 & $\begin{array}{l}\text { Scenario } \\
\text { analysis }\end{array}$ \\
\#3 & $\begin{array}{l}\text { Scenario } \\
\text { analysis }\end{array}$ \\
\hline$\# 4$ & $\begin{array}{l}\text { Scenario } \\
\text { analysis }\end{array}$ \\
\hline \#5 & $\begin{array}{l}\text { Scenario } \\
\text { analysis }\end{array}$ \\
\#6 & $\begin{array}{l}\text { Scenario } \\
\text { analysis }\end{array}$ \\
\hline
\end{tabular}
All evidence analysis (without covariates)
Base case adjusted for proportion of patients receiving ICS at baseline in each RCT
Base case excluding RCTs allowing LABAs or LAMAs during the trial, beyond study treatments
Base case adjusted for proportion patients in each RCT with severe or very severe COPD (based on GOLD criteria)
Base case adjusted for RCTs with a high proportion of patients with severe or very severe COPD ( $\geq 60 \%)$
Base case excluding RCTs that included only patients with a history of exacerbations 
(See figure on previous page.)

Figure 6 TDI network meta-analysis results at 6 months: Difference in change from baseline (CFB) or odds ratio (OR) for responders versus placebo. Bars represent 95\% Credible Interval; CFB = Change from baseline; FOR $12=$ Formoterol $12 \mu \mathrm{g}$ twice daily (BID); GPM $50=$ Glycopyrronium $50 \mu \mathrm{g}$ once daily (OD); IND $150=$ Indacaterol $150 \mu \mathrm{g}$ OD; IND $300=$ Indacaterol $300 \mu \mathrm{g}$ OD; OR= Odds ratio; SAL $50=$ Salmeterol $50 \mu \mathrm{g} \mathrm{BID;}$ TDI = Transition Dyspnoea Index; TIO 5 = Tiotropium 5 mg OD; TIO $18=$ Tiotropium $18 \mu \mathrm{g}$ OD.

outcomes out of all interventions compared. (The probability of each treatment being the best is presented in online supplement (see Additional file 1: Table S8)). Tables 1 and 2 present the treatment effect estimates for each treatment comparison for trough and post-dose $\mathrm{FEV}_{1}$, respectively. In terms of trough $\mathrm{FEV}_{1}$ all treatments are expected to be more efficacious than placebo. The largest difference in trough $\mathrm{FEV}_{1}$ was between indacaterol and formoterol (range in point estimates for difference in CFB for indacaterol 150-300 $\mu \mathrm{g}$ : 93-100 mL), although indacaterol was also more efficacious than salmeterol $50 \mu \mathrm{g}$ (72$79 \mathrm{~mL})$, tiotropium $5 \mu \mathrm{g}(41-48 \mathrm{~mL})$ and tiotropium $18 \mu \mathrm{g}$
(37-44 mL). Both glycopyrronium $50 \mu \mathrm{g}$ and tiotropium $18 \mu \mathrm{g}$ were more efficacious than formoterol $12 \mu \mathrm{g}(73 \mathrm{~mL}$ and $55 \mathrm{~mL}$, respectively) and salmeterol $50 \mu \mathrm{g}(53 \mathrm{~mL}$ and $35 \mathrm{~mL}$, respectively) in terms of trough $\mathrm{FEV}_{1}$. The availability of data for post-dose $\mathrm{FEV}_{1}$ was more limited; although the treatments were all more efficacious than placebo no differences were detected between the active treatments.

\section{St. George's Respiratory questionnaire}

In terms of health status, base case results indicated there is a $\sim 50 \%$ probability that indacaterol $150 \mu \mathrm{g}$ is the

Table 1 Results of base case NMA: Difference in intervention versus the comparator for CFB in trough FEV $\left(\mathrm{mL}^{2}\right.$ ) at 6 months, 95\% credible intervals, and probability that the intervention is better than the comparator

\begin{tabular}{|c|c|c|c|c|c|c|c|c|c|c|c|c|c|c|c|c|c|}
\hline \multirow{2}{*}{\multicolumn{2}{|c|}{ Intervention }} & \multicolumn{16}{|c|}{ Comparator } \\
\hline & & \multicolumn{2}{|c|}{ PLACEBO } & \multicolumn{2}{|c|}{ TIO 18} & \multicolumn{2}{|c|}{ SAL 50} & \multicolumn{2}{|c|}{ FOR 12} & \multicolumn{2}{|c|}{ TIO 5} & \multicolumn{2}{|c|}{ IND 150} & \multicolumn{2}{|c|}{ IND 300} & \multicolumn{2}{|c|}{ GPM 50} \\
\hline \multirow[t]{3}{*}{ PLACEBO } & estimate & & & \multicolumn{2}{|c|}{-115} & \multicolumn{2}{|c|}{-80} & \multicolumn{2}{|c|}{-60} & \multicolumn{2}{|c|}{-111} & \multicolumn{2}{|c|}{-152} & \multicolumn{2}{|c|}{-160} & \multicolumn{2}{|c|}{-133} \\
\hline & $95 \% \mathrm{Crl}$ & & & -132 & -100 & -99 & -62 & -105 & -14 & -140 & -85 & -179 & -126 & -187 & -133 & -165 & -102 \\
\hline & P(better) & & & \multicolumn{2}{|c|}{$<1 \%$} & \multicolumn{2}{|c|}{$<1 \%$} & \multicolumn{2}{|c|}{$1 \%$} & \multicolumn{2}{|c|}{$<1 \%$} & \multicolumn{2}{|c|}{$<1 \%$} & \multicolumn{2}{|c|}{$<1 \%$} & \multicolumn{2}{|c|}{$<1 \%$} \\
\hline \multirow[t]{3}{*}{ TIO 18} & estimate & \multicolumn{2}{|c|}{115} & & & & & & & & & & & & & & \\
\hline & $95 \% \mathrm{Crl}$ & 100 & 132 & & & 12 & 58 & 8 & 104 & -29 & 36 & -66 & -8 & -74 & -14 & -51 & 16 \\
\hline & P(better) & & & & & & & & & & & & & & & & \\
\hline SAL 50 & estimate & & & & & & & & & & & & & & & & \\
\hline & $95 \% \mathrm{Crl}$ & 62 & 99 & -58 & -12 & & & -28 & 70 & -65 & 2 & -102 & -42 & -111 & -47 & -89 & -17 \\
\hline & P(better) & & & & & & & & & & & & & & & & \\
\hline FOR 12 & estimate & & & & & & & & & & & & & & & & \\
\hline & $95 \% \mathrm{Crl}$ & 14 & 105 & -104 & -8 & -70 & 28 & & & -106 & 1 & -143 & -42 & -145 & -54 & -129 & -18 \\
\hline & P(better) & & & & & & & & & & & & & & & & \\
\hline $\mathrm{TIO} 5$ & estimate & & & & & & & & & & & & & & & & \\
\hline & $95 \% \mathrm{Crl}$ & 85 & 140 & -36 & 29 & -2 & 65 & -1 & 106 & & & -79 & -2 & -86 & -9 & -63 & 21 \\
\hline & P(better) & & & & & & & & & & & & & & & & \\
\hline IND 150 & estimate & & & & & & & & & & & & & & & & \\
\hline & $95 \% \mathrm{Crl}$ & 126 & 179 & 8 & 66 & 42 & 102 & 42 & 143 & 2 & 79 & & & -39 & 25 & -21 & 60 \\
\hline & P(better) & & & & & & & & & & & & & & & & \\
\hline IND 300 & estimate & & & & & & & & & & & & & & & & \\
\hline & $95 \% \mathrm{Crl}$ & 133 & 187 & 14 & 74 & 47 & 111 & 54 & 145 & 9 & 86 & -25 & 39 & & & -15 & 67 \\
\hline & P(better) & & & & & & & & & & & & & & & & \\
\hline GPM 50 & estimate & & & & & & & & & & & & & & & & \\
\hline & $95 \% \mathrm{Crl}$ & 102 & 165 & -16 & 51 & 17 & 89 & 18 & 129 & -21 & 63 & -60 & 21 & -67 & 15 & & \\
\hline & $\mathrm{P}$ (better) & & & & & & & & & & & & & & & & \\
\hline
\end{tabular}

95\% Crl $=95 \%$ Credible Interval; $P($ better $)=$ Probability of being the treatment being better than the comparator in terms of the outcome assessed; $C F B=C$ hange from baseline; $F E V_{1}=$ Forced expiratory volume; FOR $12=$ Formoterol $12 \mu \mathrm{g}$ twice daily (BID); GPM $50=$ Glycopyrronium $50 \mu \mathrm{g}$ once daily (OD); IND $150=$ Indacaterol $150 \mu \mathrm{g}$ OD; IND $300=$ Indacaterol $300 \mu \mathrm{g}$ OD; SAL 50=Salmeterol $50 \mu \mathrm{g} \mathrm{BID;} \mathrm{TIO} 5=$ Tiotropium $5 \mu \mathrm{g}$ OD; TIO $18=$ Tiotropium $18 \mu \mathrm{g}$ OD. 
Table 2 Results of base case NMA: Difference in intervention versus the comparator for CFB in post-dose FEV $(\mathrm{mL})$ at 6 months, $95 \%$ credible intervals, and probability that the intervention is better than the comparator

\begin{tabular}{|c|c|c|c|c|c|c|c|c|c|c|c|c|c|}
\hline \multirow{2}{*}{\multicolumn{2}{|c|}{ Intervention }} & \multicolumn{12}{|c|}{ Comparator } \\
\hline & & \multicolumn{2}{|c|}{ PLACEBO } & \multicolumn{2}{|c|}{ TIO 18} & \multicolumn{2}{|c|}{ SAL 50} & \multicolumn{2}{|c|}{ IND 150} & \multicolumn{2}{|c|}{ IND 300} & \multicolumn{2}{|c|}{ GPM 50} \\
\hline \multirow[t]{3}{*}{ PLACEBO } & estimate & \multirow{2}{*}{\multicolumn{2}{|c|}{0}} & \multicolumn{2}{|c|}{-202} & \multicolumn{2}{|c|}{-180} & \multicolumn{2}{|c|}{-226} & \multicolumn{2}{|c|}{-276} & \multicolumn{2}{|c|}{-213} \\
\hline & $95 \% \mathrm{Crl}$ & & & -235 & -167 & -231 & -128 & -287 & -163 & -358 & -192 & -263 & -160 \\
\hline & P(better) & & & \multicolumn{2}{|c|}{$<1 \%$} & \multicolumn{2}{|c|}{$<1 \%$} & \multicolumn{2}{|c|}{$<1 \%$} & \multicolumn{2}{|c|}{$<1 \%$} & \multicolumn{2}{|c|}{$<1 \%$} \\
\hline \multirow[t]{3}{*}{ TIO 18} & estimate & \multicolumn{2}{|c|}{202} & & & \multicolumn{2}{|c|}{23} & \multicolumn{2}{|c|}{-24} & \multicolumn{2}{|c|}{-0.074} & \multicolumn{2}{|c|}{-10} \\
\hline & $95 \% \mathrm{Crl}$ & 167 & 235 & & & -39 & 82 & -91 & 42 & -158 & 10 & -67 & 45 \\
\hline & P(better) & \multicolumn{2}{|c|}{$>99 \%$} & & & \multicolumn{2}{|c|}{$78 \%$} & \multicolumn{2}{|c|}{$22 \%$} & \multicolumn{2}{|c|}{$4 \%$} & \multicolumn{2}{|c|}{$33 \%$} \\
\hline \multirow[t]{3}{*}{ SAL 50} & estimate & & & & & & & & & & & & \\
\hline & $95 \% \mathrm{Crl}$ & 128 & 231 & -82 & 39 & & & -117 & 26 & -190 & -1 & -104 & 40 \\
\hline & P(better) & & & & & & & & & & & & \\
\hline IND 150 & estimate & & & & & & & & & & & & \\
\hline & $95 \% \mathrm{Crl}$ & 163 & 287 & -42 & 91 & -26 & 117 & & & -140 & 40 & -66 & 92 \\
\hline & P(better) & & & & & & & & & & & & \\
\hline IND 300 & estimate & & & & & & & & & & & & \\
\hline & $95 \% \mathrm{Crl}$ & 192 & 358 & -10 & 158 & 1 & 190 & -40 & 140 & & & -33 & 159 \\
\hline & P(better) & & & & & & & & & & & & \\
\hline GPM 50 & estimate & & & & & & & & & & & & \\
\hline & $95 \% \mathrm{Crl}$ & 160 & 263 & -45 & 67 & -40 & 104 & -92 & 66 & -159 & 33 & & \\
\hline & P(better) & & & & & & & & & & & & \\
\hline
\end{tabular}

95\% Crl $=95 \%$ Credible Interval; $P($ better $)=$ Probability of being the treatment being better than the comparator in terms of the outcome assessed; $C F B=$ Change from baseline; $F E V_{1}=$ Forced expiratory volume; $F O R 12=$ Formoterol $12 \mu \mathrm{g}$ twice daily (BID); GPM $50=$ Glycopyrronium $50 \mu \mathrm{g}$ once daily (OD); IND $150=$ Indacaterol $150 \mu \mathrm{g}$ OD; IND $300=$ Indacaterol $300 \mu \mathrm{g}$ OD; SAL $50=$ Salmeterol $50 \mu \mathrm{g}$ BID; TIO $5=$ Tiotropium $5 \mu \mathrm{g}$ OD; TIO 18= Tiotropium $18 \mu \mathrm{g}$ OD.

most efficacious in terms of SGRQ total score and SGRQ responders, which was followed by indacaterol $300 \mu \mathrm{g}(25 \% ; 10 \%)$, formoterol $12 \mu \mathrm{g}(6 \% ; 13 \%)$, and glycopyrronium $(15 \% ; 12 \%)$. Tables 3 and 4 present the treatment effect estimates for each treatment comparison for SGRQ total score and responders, respectively. All active treatments are expected to be more efficacious than placebo for SGRQ total score. For SGRQ response only indacaterol $150 \mu \mathrm{g}$ and $300 \mu \mathrm{g}$, tiotropium $18 \mu \mathrm{g}$ and glycopyrronium $50 \mu \mathrm{g}$ were more efficacious than placebo, whereas the credible intervals for the other treatment estimates versus placebo include 1 . With respect to SGRQ total score, indacaterol was more efficacious than salmeterol $50 \mu \mathrm{g}$ (indacaterol $150 \mu \mathrm{g} / 300 \mu \mathrm{g}$ difference point estimates ranging from -2.26 to -2.56 points), as was glycopyrronium $50 \mu \mathrm{g}(-1.87$ points) and tiotropium $18 \mu \mathrm{g}$ (-1.32 points), although an improved response was only observed for the comparison of indacaterol $150 \mu \mathrm{g}$ versus salmeterol (odds ratio (OR) of 1.42).

\section{Transition dyspnoea index}

For TDI, base case results suggest there is an $86 \%$ probability that indacaterol $300 \mu \mathrm{g}$ is the best treatment as measured with the total score; In a responder analysis using TDI, a 95\% probability was obtained with indacaterol
$300 \mu \mathrm{g}$, which was followed by formoterol $12 \mu \mathrm{g}(4 \%)$, and indacaterol $150 \mu \mathrm{g}(1 \%)$, and glycopyrronium (1\%). Tables 5 and 6 present the treatment effect estimates for each treatment comparison for TDI total score and responders, respectively. Indacaterol $300 \mu \mathrm{g}$ and tiotropium were more efficacious than salmeterol $50 \mu \mathrm{g}$ in terms of total score (difference of 0.58 and 0.32 , respectively) and indacaterol $300 \mu \mathrm{g}$ was also more efficacious than formoterol $12 \mu \mathrm{g}$ (difference of 0.58). A greater response was observed with indacaterol $300 \mu \mathrm{g}$ in comparison to salmeterol $50 \mu \mathrm{g}$ (OR of 1.70), tiotropium $18 \mu \mathrm{g}$ (OR of 1.56), glycopyrronium $50 \mu \mathrm{g}(\mathrm{OR}=1.52)$ and indacaterol $150 \mu \mathrm{g}(\mathrm{OR}$ of 1.39).

\section{Scenario analyses}

An overview of the NMA results for the continuous outcomes at 6 months is presented in Figure 7 for the different scenarios using symbols to summarize the main conclusion for each comparison and analysis. Treatment effect estimates were most sensitive to adjustment for disease severity (i.e. degree of airflow limitation). Results were less sensitive to adjustment for concomitant ICS use or concomitant LABA or LAMA use. Minimal changes were observed by excluding studies that required an exacerbation history. Overall, the different meta-regression analyses 
Table 3 Results of base case NMA: Difference in intervention versus the comparator for CFB in SGRQ total score at 6 months, $95 \%$ credible intervals, and probability that the intervention is better than the comparator

\begin{tabular}{|c|c|c|c|c|c|c|c|c|c|c|c|c|c|c|c|}
\hline \multirow{2}{*}{\multicolumn{2}{|c|}{ Intervention }} & \multicolumn{14}{|c|}{ Comparator } \\
\hline & & \multirow{3}{*}{$\begin{array}{c}\text { PLACEBO } \\
0.00\end{array}$} & \multicolumn{2}{|c|}{ TIO 18} & \multicolumn{2}{|c|}{ SAL 50} & \multicolumn{2}{|c|}{ FOR 12} & \multicolumn{2}{|c|}{ TIO 5} & \multicolumn{2}{|c|}{ IND 150} & \multicolumn{2}{|c|}{ IND 300} & GPM 50 \\
\hline \multirow[t]{3}{*}{ PLACEBO } & estimate & & \multicolumn{2}{|c|}{2.63} & \multicolumn{2}{|c|}{1.31} & \multicolumn{2}{|c|}{2.58} & \multicolumn{2}{|c|}{2.21} & \multicolumn{2}{|c|}{3.87} & \multicolumn{2}{|c|}{3.57} & 3.18 \\
\hline & $95 \% \mathrm{Crl}$ & & 1.91 & 3.31 & 0.48 & 2.21 & 0.60 & 4.53 & 0.78 & 3.61 & 2.56 & 5.17 & 2.30 & 4.84 & $1.78 \quad 4.56$ \\
\hline & P(better) & & \multicolumn{2}{|c|}{$<1 \%$} & \multicolumn{2}{|c|}{$<1 \%$} & \multicolumn{2}{|c|}{$1 \%$} & \multicolumn{2}{|c|}{$<1 \%$} & \multicolumn{2}{|c|}{$<1 \%$} & \multicolumn{2}{|c|}{$<1 \%$} & $<1 \%$ \\
\hline \multirow[t]{3}{*}{$\mathrm{TIO} 18$} & estimate & -2.63 & \multicolumn{2}{|c|}{0.00} & \multicolumn{2}{|c|}{-1.32} & -0 & & -0 & & 1.2 & & 0.9 & & 0.55 \\
\hline & $95 \% \mathrm{Crl}$ & $\begin{array}{ll}-3.31 & -1.91\end{array}$ & & & -2.32 & -0.21 & -2.09 & 2.01 & -1.98 & 1.17 & -0.15 & 2.63 & -0.41 & 2.31 & $\begin{array}{ll}-0.92 & 2.04\end{array}$ \\
\hline & P(better) & $>99 \%$ & & & 99 & & 52 & & & & 4 & & 89 & & $22 \%$ \\
\hline SAL 50 & estimate & -1.31 & 1. & & 0. & & 1.2 & & 0. & & 2. & & 2.2 & & 1.87 \\
\hline & $95 \% \mathrm{Crl}$ & $-2.21 \quad-0.48$ & 0.21 & 2.32 & & & -0.92 & 3.36 & -0.82 & 2.50 & 1.03 & 4.00 & 0.74 & 3.75 & $0.21 \quad 3.44$ \\
\hline & $\mathrm{P}$ (better) & $>99 \%$ & 1 & & & & 12 & & 13 & & $<1$ & & $<1$ & & $1 \%$ \\
\hline FOR 12 & estimate & -2.58 & 0. & & -1 & & 0.0 & & -0 & & 1. & & 1.0 & & 0.61 \\
\hline & $95 \% \mathrm{Crl}$ & $-4.53-0.60$ & -2.01 & 2.09 & -3.36 & 0.92 & & & -2.78 & 2.05 & -0.97 & 3.56 & -0.96 & 2.98 & $\begin{array}{ll}-1.81 \quad 3.02\end{array}$ \\
\hline & $P($ better $)$ & $99 \%$ & 48 & & 88 & & & & 6 & & 13 & & 16 & & $31 \%$ \\
\hline TIO 5 & estimate & -2.21 & 0. & & -0 & & 0.3 & & 0. & & 1. & & 1.3 & & 0.97 \\
\hline & $95 \% \mathrm{Crl}$ & $-3.61 \quad-0.78$ & -1.17 & 1.98 & -2.50 & 0.82 & -2.05 & 2.78 & & & -0.29 & 3.58 & -0.53 & 3.26 & $\begin{array}{ll}-1.01 \quad 2.94\end{array}$ \\
\hline & P(better) & $>99 \%$ & 28 & & 87 & & 38 & & & & 4 & & 70 & & $15 \%$ \\
\hline IND 150 & estimate & -3.87 & -1 & & -2 & & -1 & & -1 & & 0. & & -0 & & -0.70 \\
\hline & $95 \% \mathrm{Crl}$ & $-5.17 \quad-2.56$ & -2.63 & 0.15 & -4.00 & -1.03 & -3.56 & 0.97 & -3.58 & 0.29 & & & -1.82 & 1.24 & $\begin{array}{ll}-2.59 & 1.28\end{array}$ \\
\hline & P(better) & $>99 \%$ & 96 & & $>9$ & & 87 & & 96 & & & & 65 & & $77 \%$ \\
\hline IND 300 & estimate & -3.57 & -0 & & -2 & & -1 & & -1 & & 0. & & 0.0 & & -0.39 \\
\hline & $95 \% \mathrm{Crl}$ & $-4.84 \quad-2.30$ & -2.31 & 0.41 & -3.75 & -0.74 & -2.98 & 0.96 & -3.26 & 0.53 & -1.24 & 1.82 & & & $\begin{array}{ll}-2.28 & 1.47\end{array}$ \\
\hline & $\mathrm{P}$ (better) & $>99 \%$ & 92 & & $>9$ & & 84 & & 9 & & 35 & & & & $66 \%$ \\
\hline GPM 50 & estimate & -3.18 & -0 & & -1 & & -0 & & -0 & & 0. & & 0.3 & & 0.00 \\
\hline & $95 \% \mathrm{Crl}$ & $-4.56 \quad-1.78$ & -2.04 & 0.92 & -3.44 & -0.21 & -3.02 & 1.81 & -2.94 & 1.01 & -1.28 & 2.59 & -1.47 & 2.28 & \\
\hline & P(better) & $>99 \%$ & 78 & & 99 & & 69 & & 85 & & 23 & & 34 & & \\
\hline
\end{tabular}

95\% $\mathrm{Crl}=95 \%$ Credible Interval; $P$ (better) = Probability of being the treatment being better than the comparator in terms of the outcome assessed; $C F B=C$ ange from baseline; FOR $12=$ Formoterol $12 \mu \mathrm{g}$ twice daily (BID); GPM 50= Glycopyrronium $50 \mu \mathrm{g}$ once daily (OD); IND $150=$ Indacaterol $150 \mu \mathrm{g}$ OD; IND $300=$ Indacaterol $300 \mu \mathrm{g}$ $\mathrm{OD} ; \mathrm{SAL} 50=$ Salmeterol $50 \mu \mathrm{g}$ BID; $S G R Q=$ St. George's Respiratory Questionnaire; TIO $5=$ Tiotropium $5 \mu \mathrm{g}$ OD; TIO $18=$ Tiotropium $18 \mu \mathrm{g}$ OD.

resulted in minimal changes in the treatment effect estimates and did not alter the interpretation.

\section{Discussion}

The objective of this analysis was to compare the efficacy of individual bronchodilators for patients with moderate to severe COPD in terms of lung function, health status, and dyspnoea. Based on the results of the NMA at 6 months, indacaterol resulted in the best treatment at either the 150 or $300 \mu \mathrm{g}$ dose, depending on the outcome assessed, although indacaterol was not always more efficacious than the alternative bronchodilators and differences versus other active treatments were small.

Thresholds for clinically important differences have been established for active treatments versus placebo in terms of $\mathrm{FEV}_{1}$, SGRQ total score, and TDI total score. Although comparisons of alternative active treatments may not be expected to reach these thresholds, in the absence of any clear guidance for interpretation of active treatments these thresholds have been used to help identify whether differences between treatments are clinically relevant. $\mathrm{FEV}_{1}$ thresholds defined to evaluate whether an active treatment has demonstrated a clinically meaning difference versus placebo (i.e. $100 \mathrm{~mL}-140 \mathrm{~mL}$ [64-66]) suggest that none of the differences in lung function between the active treatments were clinically meaningful in the analysis of all studies without covariates (basecase analysis). In terms of health status, improvements in SGRQ total score were identified for indacaterol 150 and $300 \mu \mathrm{g}$, glycopyrronium $50 \mu \mathrm{g}$, and tiotropium 18 $\mu \mathrm{g}$ in comparison to salmeterol, although differences were less than the 4 units for a clinically relevant difference. Only indacaterol $150 \mu \mathrm{g}$ led to a clinically relevant response relative to salmeterol with respect to SGRQ. The estimated differences between treatments in terms of TDI total score were smaller than the threshold for 
Table 4 Results of base case NMA: Difference in intervention versus the comparator for SGRQ responders at 6 months in terms of odds ratios (ORs), $95 \%$ credible intervals, and probability that the intervention is better than the comparator

\begin{tabular}{|c|c|c|c|c|c|c|c|c|c|c|c|c|c|c|c|c|c|}
\hline \multirow[b]{2}{*}{ Intervention } & & \multicolumn{16}{|c|}{ Comparator } \\
\hline & & \multicolumn{2}{|c|}{ PLACEBO } & \multicolumn{2}{|c|}{ TIO 18} & \multicolumn{2}{|c|}{ SAL 50} & \multicolumn{2}{|c|}{ FOR 12} & \multicolumn{2}{|c|}{ TIO 5} & \multicolumn{2}{|c|}{ IND 150} & \multicolumn{2}{|c|}{ IND 300} & \multicolumn{2}{|c|}{ GPM 50} \\
\hline \multirow[t]{3}{*}{ PLACEBO } & estimate & & & \multicolumn{2}{|c|}{0.71} & \multicolumn{2}{|c|}{0.84} & \multicolumn{2}{|c|}{0.71} & \multicolumn{2}{|c|}{0.70} & \multicolumn{2}{|c|}{0.60} & \multicolumn{2}{|c|}{0.67} & \multicolumn{2}{|c|}{0.69} \\
\hline & $95 \% \mathrm{Crl}$ & & & 0.61 & 0.83 & 0.70 & 1.00 & 0.48 & 1.07 & 0.49 & 1.00 & 0.47 & 0.77 & 0.52 & 0.87 & 0.52 & 0.92 \\
\hline & P(better) & & & \multicolumn{2}{|c|}{$<1 \%$} & \multicolumn{2}{|c|}{$9 \%$} & \multicolumn{2}{|c|}{$5 \%$} & \multicolumn{2}{|c|}{$3 \%$} & \multicolumn{2}{|c|}{$<1 \%$} & \multicolumn{2}{|c|}{$<1 \%$} & \multicolumn{2}{|c|}{$1 \%$} \\
\hline \multirow[t]{3}{*}{ TIO 18} & estimate & \multicolumn{2}{|c|}{1.41} & & & & & 1. & & & & & & & & & \\
\hline & $95 \% \mathrm{Crl}$ & 1.21 & 1.64 & & & 0.92 & 1.58 & 0.65 & 1.58 & 0.66 & 1.50 & 0.64 & 1.14 & 0.71 & 1.29 & 0.71 & 1.35 \\
\hline & $\mathrm{P}$ (better) & & & & & & & & & & & & & & & & \\
\hline SAL 50 & estimate & & & & & & & & & & & & & & & & \\
\hline & $95 \% \mathrm{Crl}$ & 1.00 & 1.42 & 0.63 & 1.09 & & & 0.53 & 1.34 & 0.54 & 1.27 & 0.52 & 0.96 & 0.57 & 1.11 & 0.56 & 1.17 \\
\hline & P(better) & & & & & & & & & & & & & & & & \\
\hline FOR 12 & estimate & & & & & & & 1. & & & & & & & & & \\
\hline & $95 \% \mathrm{Crl}$ & 0.93 & 2.10 & 0.63 & 1.55 & 0.74 & 1.90 & & & 0.58 & 1.68 & 0.53 & 1.33 & 0.63 & 1.42 & 0.59 & 1.58 \\
\hline & P(better) & & & & & & & & & & & & & & & & \\
\hline TlO 5 & estimate & & & & & & & & & & & & & & & & \\
\hline & $95 \% \mathrm{Crl}$ & 1.00 & 2.03 & 0.67 & 1.52 & 0.79 & 1.87 & 0.60 & 1.74 & & & 0.56 & 1.32 & 0.63 & 1.49 & 0.62 & 1.55 \\
\hline & P(better) & & & & & & & & & & & & & & & & \\
\hline IND 150 & estimate & & & & & & & 1. & & & & & & & & & \\
\hline & $95 \% \mathrm{Crl}$ & 1.29 & 2.13 & 0.88 & 1.57 & 1.04 & 1.92 & 0.75 & 1.88 & 0.76 & 1.79 & & & 0.83 & 1.51 & 0.78 & 1.67 \\
\hline & P(better) & & & & & & & 80 & & & & & & & & & \\
\hline IND 300 & estimate & & & & & & & 1. & & & & & & & & & \\
\hline & $95 \% \mathrm{Crl}$ & 1.15 & 1.91 & 0.78 & 1.41 & 0.90 & 1.76 & 0.71 & 1.59 & 0.67 & 1.60 & 0.66 & 1.20 & & & 0.70 & 1.49 \\
\hline & P(better) & & & & & & & 6 & & & & & & & & & \\
\hline GPM 50 & estimate & & & & & & & 1. & & & & & & & & & \\
\hline & $95 \% \mathrm{Crl}$ & 1.08 & 1.94 & 0.74 & 1.42 & 0.85 & 1.79 & 0.63 & 1.71 & 0.65 & 1.61 & 0.60 & 1.27 & 0.67 & 1.43 & & \\
\hline & $\mathrm{P}$ (better) & & & & & & & & & & & & & & & & \\
\hline
\end{tabular}

95\% Crl = 95\% Credible Interval; $P$ (better) = Probability of being the treatment being better than the comparator in terms of the outcome assessed; FOR $12=$ Formoterol $12 \mu \mathrm{g}$ twice daily (BID); GPM $50=$ Glycopyrronium $50 \mu \mathrm{g}$ once daily (OD); IND $150=$ Indacaterol $150 \mu \mathrm{g}$ OD; IND $300=$ Indacaterol $300 \mu \mathrm{g}$ OD; $O R=$ Odds ratio; $S A L 50=$ Salmeterol $50 \mu \mathrm{g}$ BID; SGRQ = St. George's Respiratory Questionnaire; TIO $5=$ Tiotropium $5 \mu \mathrm{g}$ OD; $T I O$ 18= Tiotropium $18 \mu \mathrm{g}$ OD.

clinically relevant difference of 1 point. A greater proportion of patients had a clinically relevant TDI response with indacaterol $300 \mu \mathrm{g}$ in comparison to salmeterol $50 \mu \mathrm{g}$ and tiotropium $18 \mu \mathrm{g}$.

The validity of the findings depends on the quality of the RCTs and the extent of any violations in the similarity and consistency assumptions across studies [22]. In a network meta-analysis of RCTs involving multiple treatment comparisons, the randomization holds only within the individual trials, and not across trials. If the different direct comparisons show systematic differences in study and patient characteristics, and these differences are treatment effect modifiers, then the estimates of any indirect comparison as obtained with the network metaanalysis will be biased. With a meta-regression analysis we aim to minimize this confounding bias by adjusting for inconsistencies in the evidence base.
The trials included in the network meta-analysis were generally of good quality. All trials were blinded with the exception of open label tiotropium $18 \mu \mathrm{g}$ in three RCTs, which has been shown to be comparable to blinded results for $\mathrm{FEV}_{1}$, although with some minimal bias introduced on more subjective measures [67]. However, some differences across trials were identified in terms of concomitant ICS use, concomitant LABA or LAMA use, the severity of COPD and the exacerbation history requirements. Individual scenario analyses were performed to evaluate these differences using a either a metaregression model or by excluding specific studies that differed in terms of the characteristics identified. Overall, the interpretation of findings obtained with analysis based on all studies without adjustment for covariates (base-case analysis) was the same as obtained with the scenario analyses in the majority of cases. Only a few 
Table 5 Results of base case NMA: Difference in intervention versus the comparator for TDI total score at 6 months, $\mathbf{9 5 \%}$ credible intervals, and probability that the intervention is better than the comparator

\begin{tabular}{|c|c|c|c|c|c|c|c|c|c|c|c|c|c|c|c|}
\hline \multirow{2}{*}{\multicolumn{2}{|c|}{ Intervention }} & \multicolumn{14}{|c|}{ Comparator } \\
\hline & & \multicolumn{2}{|c|}{ PLACEBO } & \multicolumn{2}{|c|}{ TIO 18} & \multicolumn{2}{|c|}{ SAL 50} & \multicolumn{2}{|c|}{ FOR 12} & \multicolumn{2}{|c|}{ IND 150} & \multicolumn{2}{|c|}{ IND 300} & \multicolumn{2}{|c|}{ GPM 50} \\
\hline \multirow[t]{3}{*}{ PLACEBO } & estimate & \multirow{2}{*}{\multicolumn{2}{|c|}{0.00}} & \multicolumn{2}{|c|}{-0.96} & \multicolumn{2}{|c|}{-0.64} & \multicolumn{2}{|c|}{-0.65} & \multicolumn{2}{|c|}{-0.93} & \multicolumn{2}{|c|}{-1.23} & \multicolumn{2}{|c|}{-0.92} \\
\hline & $95 \% \mathrm{Crl}$ & & & -1.20 & -0.74 & -0.91 & -0.38 & -1.09 & -0.20 & -1.20 & -0.65 & -1.51 & -0.95 & -1.27 & -0.58 \\
\hline & P(better) & & & \multicolumn{2}{|c|}{$<1 \%$} & \multicolumn{2}{|c|}{$<1 \%$} & \multicolumn{2}{|c|}{$<1 \%$} & \multicolumn{2}{|c|}{$<1 \%$} & \multicolumn{2}{|c|}{$<1 \%$} & \multicolumn{2}{|c|}{$<1 \%$} \\
\hline \multirow[t]{3}{*}{$\mathrm{TIO} 18$} & estimate & & & \multicolumn{2}{|c|}{0.000} & \multicolumn{2}{|c|}{0.32} & \multicolumn{2}{|c|}{0.32} & \multicolumn{2}{|c|}{0.04} & \multicolumn{2}{|c|}{-0.27} & \multicolumn{2}{|c|}{0.046} \\
\hline & $95 \% \mathrm{Crl}$ & 0.741 & 1.195 & & & 0.012 & 0.64 & -0.17 & 0.81 & -0.28 & 0.37 & -0.59 & 0.07 & -0.33 & 0.43 \\
\hline & $\mathrm{P}$ (better) & & & & & & & & $\%$ & & & & & & \\
\hline SAL 50 & estimate & & & & & & & & 0 & & & & 58 & & \\
\hline & $95 \% \mathrm{Crl}$ & 0.38 & 0.91 & -0.64 & -0.01 & & & -0.52 & 0.51 & -0.63 & 0.06 & -0.96 & -0.22 & -0.71 & 0.14 \\
\hline & P(better) & & & & & & & & $\%$ & & & & $\%$ & & \\
\hline FOR 12 & estimate & & & & & & & & 0 & & & & 58 & & \\
\hline & $95 \% \mathrm{Crl}$ & 0.20 & 1.09 & -0.81 & 0.17 & -0.51 & 0.52 & & & -0.77 & 0.22 & -1.02 & -0.14 & -0.83 & 0.29 \\
\hline & P(better) & & & & & & & & & & & & & & \\
\hline IND 150 & estimate & & & & & & & & 28 & & & & & & \\
\hline & $95 \% \mathrm{Crl}$ & 0.65 & 1.20 & -0.37 & 0.28 & -0.06 & 0.63 & -0.22 & 0.77 & & & -0.63 & 0.02 & -0.43 & 0.45 \\
\hline & $\mathrm{P}$ (better) & & & & & & & & $\%$ & & & & & & \\
\hline IND 300 & estimate & & & & & & & & 58 & & & & & & \\
\hline & $95 \% \mathrm{Crl}$ & 0.95 & 1.51 & -0.07 & 0.59 & 0.22 & 0.96 & 0.14 & 1.02 & -0.02 & 0.63 & & & -0.13 & 0.75 \\
\hline & P(better) & & & & & & & & $\%$ & & & & & & \\
\hline GPM 50 & estimate & & & & & & & & 27 & & & & & & \\
\hline & $95 \% \mathrm{Crl}$ & 0.58 & 1.27 & -0.43 & 0.33 & -0.14 & 0.71 & -0.29 & 0.83 & -0.45 & 0.43 & -0.75 & 0.13 & & \\
\hline & P(better) & & & & & & & & $\%$ & & & & & & \\
\hline
\end{tabular}

95\% Crl $=95 \%$ Credible Interval; $P($ better $)=$ Probability of being the treatment being better than the comparator in terms of the outcome assessed; FOR $12=$ Formoterol $12 \mu \mathrm{g}$ twice daily (BID); GPM 50= Glycopyrronium $50 \mu \mathrm{g}$ once daily (OD); IND $150=$ Indacaterol $150 \mu \mathrm{g}$ OD; IND $300=$ Indacaterol $300 \mu \mathrm{g}$ OD; SAL $50=$ Salmeterol $50 \mu \mathrm{g}$ BID; TIO 5 = Tiotropium $5 \mu \mathrm{g}$ OD; TIO $18=$ Tiotropium $18 \mu \mathrm{g}$ OD; TDI = Transitional Dyspnoea Index.

scenarios suggest a slight difference in the strength of the comparative effects.

Although we went to great lengths to assess whether the network meta-analysis was biased by systematic differences between studies, the meta-regression analysis was based on study level data which has limitations. First of all, it was not feasible to include all covariates of interest simultaneously due to the limited number of data points. Second, study and patient characteristics were not consistently reported. For example, limited information was available for the exacerbation history of patients and therefore it was only possible to exclude trials that clearly required an exacerbation history. Similarly, information regarding COPD comorbidities was not consistently reported across the RCTs, so these potential differences could not be explored. Third, it is well known that meta-regression analysis based on study level data can be prone to ecological bias, which means that association between study level patient characteristics and the treatment effects may not reflect the individual-level effect modification of that covariate. As such, it has to be accepted that there is the risk of residual confounding bias.

This study aimed to provide a comprehensive evidence base. However, it was not possible to capture all recent studies. The literature search did not capture the ACCORD [68] or ATTAIN [69] trials evaluating aclidinium $400 \mu \mathrm{g}$ BID that were published after the date of the search, and an updated analysis including these studies is of interest. Moreover, data for new bronchodilators that may be of interest, such as vilanterol, olodaterol, and unmeclidinium, were not available and may necessitate an updated analysis including these treatments in future. It should also be noted, that in order to include the indacaterol and glycopyrronium trials that were not yet published at the time of the literature search, Novartis provided the corresponding clinical study reports. No attempt was made to obtain study reports from manufacturers of formoterol, salmeterol, or tiotropium. This may have induced a bias, but it is unlikely that key positive results were withheld from the primary papers. 
Table 6 Results of base case NMA: Difference in intervention versus the comparator for TDI responders at 6 months in terms of odds ratios (ORs), $95 \%$ credible intervals, and probability that the intervention is better than the comparator

\begin{tabular}{|c|c|c|c|c|c|c|c|c|c|c|c|c|c|c|c|}
\hline \multirow[b]{2}{*}{ Intervention } & & \multicolumn{14}{|c|}{ Comparator } \\
\hline & & \multicolumn{2}{|c|}{ PLACEBO } & \multicolumn{2}{|c|}{ TIO 18} & \multicolumn{2}{|c|}{ SAL 50} & \multicolumn{2}{|c|}{ FOR 12} & \multicolumn{2}{|c|}{ IND 150} & \multicolumn{2}{|c|}{ IND 300} & \multicolumn{2}{|c|}{ GPM 50} \\
\hline \multirow[t]{3}{*}{ PLACEBO } & estimate & & & \multicolumn{2}{|c|}{0.61} & \multicolumn{2}{|c|}{0.67} & \multicolumn{2}{|c|}{0.53} & \multicolumn{2}{|c|}{0.55} & \multicolumn{2}{|c|}{0.39} & \multicolumn{2}{|c|}{0.60} \\
\hline & $95 \% \mathrm{Crl}$ & & & 0.51 & 0.73 & 0.54 & 0.82 & 0.38 & 0.74 & 0.44 & 0.68 & 0.31 & 0.49 & 0.47 & 0.76 \\
\hline & P(better) & & & \multicolumn{2}{|c|}{$<1 \%$} & \multicolumn{2}{|c|}{$<1 \%$} & \multicolumn{2}{|c|}{$<1 \%$} & \multicolumn{2}{|c|}{$<1 \%$} & \multicolumn{2}{|c|}{$<1 \%$} & \multicolumn{2}{|c|}{$<1 \%$} \\
\hline \multirow[t]{3}{*}{ TIO 18} & estimate & & & \multicolumn{2}{|c|}{1.00} & \multicolumn{2}{|c|}{1.09} & \multicolumn{2}{|c|}{0.86} & \multicolumn{2}{|c|}{0.89} & \multicolumn{2}{|c|}{0.64} & \multicolumn{2}{|c|}{0.97} \\
\hline & $95 \% \mathrm{Crl}$ & 1.37 & 1.96 & & & 0.88 & 1.37 & 0.59 & 1.26 & 0.70 & 1.14 & 0.50 & 0.83 & 0.75 & 1.27 \\
\hline & P(better) & \multicolumn{2}{|c|}{$>99 \%$} & & & & & & & & & & & & \\
\hline SAL 50 & estimate & & & & & & & & & & & & & & \\
\hline & $95 \% \mathrm{Crl}$ & 1.21 & 1.84 & 0.73 & 1.14 & & & 0.54 & 1.17 & 0.63 & 1.06 & 0.44 & 0.78 & 0.66 & 1.21 \\
\hline & P(better) & & & & & & & & & & & & & & \\
\hline FOR 12 & estimate & & & & & & & & & & & & & & \\
\hline & $95 \% \mathrm{Crl}$ & 1.35 & 2.66 & 0.80 & 1.68 & 0.85 & 1.87 & & & 0.70 & 1.52 & 0.53 & 1.04 & 0.74 & 1.71 \\
\hline & P(better) & & & & & & & & & & & & & & \\
\hline IND 150 & estimate & & & & & & & & & & & & & & \\
\hline & $95 \% \mathrm{Crl}$ & 1.48 & 2.28 & 0.88 & 1.44 & 0.95 & 1.58 & 0.66 & 1.43 & & & 0.55 & 0.94 & 0.80 & 1.50 \\
\hline & P(better) & & & & & & & & & & & & & & \\
\hline IND 300 & estimate & & & & & & & & & & & & & & \\
\hline & $95 \% \mathrm{Crl}$ & 2.04 & 3.19 & 1.21 & 2.02 & 1.28 & 2.28 & 0.97 & 1.89 & 1.07 & 1.81 & & & 1.10 & 2.10 \\
\hline & P(better) & & & & & & & & & & & & & & \\
\hline GPM 50 & estimate & & & & & & & & & & & & & & \\
\hline & $95 \% \mathrm{Crl}$ & 1.32 & 2.14 & 0.79 & 1.34 & 0.82 & 1.52 & 0.58 & 1.35 & 0.67 & 1.26 & 0.48 & 0.91 & & \\
\hline & P(better) & & & & & & & & & & & & & & \\
\hline
\end{tabular}

95\% Crl $=95 \%$ Credible Interval; $P$ (better) = Probability of being the treatment being better than the comparator in terms of the outcome assessed; FOR $12=$ Formoterol $12 \mu \mathrm{g}$ twice daily (BID); GPM $50=$ Glycopyrronium $50 \mu \mathrm{g}$ once daily (OD); IND $150=$ Indacaterol $150 \mu \mathrm{g}$ OD; IND $300=$ Indacaterol $300 \mu \mathrm{g}$ OD; $O R=$ Odds ratio; SAL $50=$ Salmeterol $50 \mu \mathrm{g}$ BID; TIO $5=$ Tiotropium $5 \mu \mathrm{g}$ OD; TIO $18=$ Tiotropium $18 \mu \mathrm{O}$ OD; TDI=Transitional Dyspnoea Index.

The current paper focussed on the 6 month time point, but results at 12 weeks are available as well (online Additional file 1). Results at 6 months provide better insight regarding efficacy over a longer term than the 12 week results, particularly for patient reported outcomes, but data for the approved dose of indacaterol in the United States $(75 \mu \mathrm{g})$ are only available at 12 weeks. There is also a need to evaluate whether there is sufficient data available to inform decision-makers regarding longer term comparative efficacy. One potential limitation of the current analysis is that some studies were excluded from the analysis if the outcomes reported deviated by more than 2 weeks from the specified time points of interest. For example, the analyses of SGRQ and trough $\mathrm{FEV}_{1}$ at the 6 months excluded data from Stockley et al. 2006 ( $\mathrm{n}=634)$, and Chan et al. $2007(\mathrm{n}=913)$, which may have influenced the results somewhat for salmeterol and tiotropium. However, given the large number of studies included for these treatments, the exclusion of these trials is not expected to have a large impact. Similarly, only postdose $\mathrm{FEV}_{1}$ results at 2 hours after dosing were included, which reflected the most commonly reported time point.
Although several network meta-analyses have been published in the area of COPD, it is challenging to compare the current results to previous analyses. Earlier analyses did not include indacaterol [70,71], and more recent analyses have focussed on comparisons to fixed-dose combinations $[72,73]$ or were not as comprehensive in terms of the data or outcomes evaluated. For example, the analysis by Cope et al. 2012 [74] was restricted to four trials from the indacaterol trial program and the review by Cope et al. 2012 [75] focussed on trough $\mathrm{FEV}_{1}$ and SGRQ total score at 12 weeks. Furthermore, these studies did not include evidence regarding treatments such as glycopyrronium $50 \mu \mathrm{g}$ or tiotropium $5 \mu \mathrm{g}$. Recent meta-analyses restricted the evidence to RCTs that directly compared the active interventions of interest [76,77] or placebo controlled trials [78] without considering the full network of evidence. Also, in some cases alternative LABAs were pooled together (i.e. formoterol, salmeterol, and/or indacaterol), despite potential differences in these treatments, preventing a clear comparison to the current results. Therefore, to our knowledge, the current study generates new evidence regarding the efficacy of monotherapies for moderate to severe COPD. 


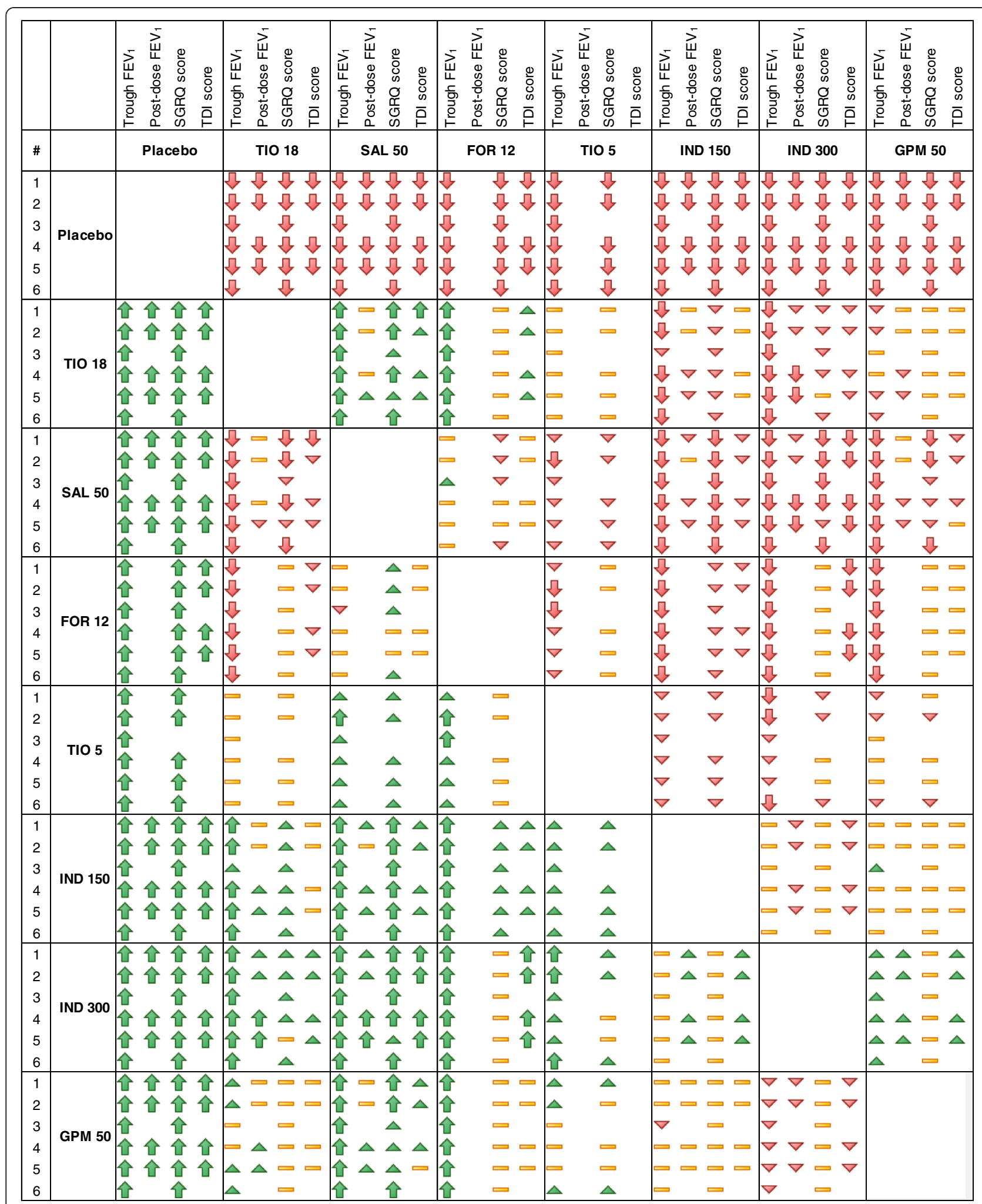

Figure 7 Overview of the network meta-analysis results for trough $\mathrm{FEV}_{1}$, post-dose FEV 1 , SGRQ total score, and TDI total score at 6 months. Symbols are explained in Figure $1 ; F_{1} F_{1}=$ Forced expiratory volume in 1 second; FOR $12=$ Formoterol $12 \mu g$ twice daily (BID); GPM $50=$ Glycopyrronium $50 \mu \mathrm{g}$ once daily (OD); IND 150 = Indacaterol $150 \mu \mathrm{g}$ OD; IND $300=$ Indacaterol $300 \mu \mathrm{g}$ OD; SAL $50=$ Salmeterol $50 \mu \mathrm{g}$

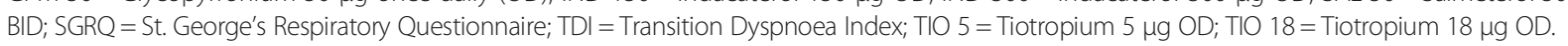


The efficacy outcomes analyzed here provide insight into a broad range of clinically relevant outcomes. $\mathrm{FEV}_{1}$ is often a primary endpoint and reflects an important outcome from a clinical and regulatory perspective, providing a reproducible and objective measurement of airflow limitation [1]. SGRQ and TDI are based on validated instruments and provide unique insight into the patient perspective. Exacerbations reflect another key outcome given their impact on quality of life and resource utilization, although a separate publication will be developed in order to capture the complexity associated with these outcomes. It should be acknowledged that no safety outcomes were assessed, which is a critical aspect of decision-making that has been addressed by others [79-83].

In conclusion, based on the results of the NMA, indacaterol, glycopyrronium, and tiotropium are expected to be the most favourable bronchodilators in terms of lung function, health status, and dyspnoea at six months, although differences were only clinically meaningful for indacaterol $150 \mu \mathrm{g}$ in comparison to salmeterol in terms of SGRQ and for indacaterol $300 \mu \mathrm{g}$ in comparison to salmeterol, tiotropium and formoterol in terms of TDI response.

\section{Additional file}

Additional file 1: RCT study and patient characteristics, individual study results, flow diagram, and NMA results at 12 weeks. Table S1. Key study characteristics for RCTs included in the network meta-analysis. Table S2. Individual study results for trough $\mathrm{FEV}_{1}$ at 12 weeks and 6 months $(\mathrm{mL})$ : difference in change from baseline (CFB) for treatment versus comparator. Table S3. Individual study results for post-dose $\mathrm{FEV}_{1}$ at 12 weeks and 6 months ( $\mathrm{mL}$ ): difference in change from baseline (CFB) for treatment versus comparator. Table S4. Individual study results for SGRQ total score at 12 weeks and 6 months: difference in change from baseline (CFB) for treatment versus comparator. Table S5. Individual study results for SGRQ responders at 12 weeks and 6 months: $n / \mathrm{N}$ (proportion responders) for each treatment. Table S6. Individual study results for TDI total score at 12 weeks and 6 months: difference in change from baseline (CFB) for treatment versus comparator. Table S7. Individual study results for TDI responders at 12 weeks and 6 months: $\mathrm{n} / \mathrm{N}$ (proportion responders) for each treatment. Table $\mathbf{S 8 .}$ Results of base case network meta-analysis: Probability of each treatment being the best in terms of trough and post-dose $F E V_{1}(\mathrm{~mL}), \mathrm{SGRQ}$ total score and response, and TDI total score and response at 6 months. Figure S1. Flow diagram of study selection. Figure $\mathbf{S 2}$. Trough and post-dose FEV 1 network meta-analysis results at 12 weeks: Difference in change from baseline (CFB) versus placebo. Figure S3. SGRQ total score network meta-analysis results at 6 months: Difference in change from baseline (CFB) or odds ratio (OR) versus placebo. Figure S4. TDI total score network meta-analysis results at 6 months: Difference in change from baseline (CFB) or odds ratio (OR) versus placebo.

\section{Competing interests}

SC, JJ, FB, and AE are employees of Mapi and received funding from Novartis for the study. JD and PJ received no compensation for working on this manuscript. JD served as a consultant for Novartis and received and honorarium in the area of drug development. PJ has received honorarium for speaker fees and/or advisory boards from Almirall, AstraZeneca, Bayer, GlaxoSmithKline, Merck, Novartis, Roche, Spiration. St. George's University of London has received consulting fees for work that PJ has performed for Almirall, GlaxoSmithKline, and Novartis. MK was a full time employee of Novartis Pharma AG until February 2013. GC is a full time employee of
Novartis Pharma AG and has shares in the company. MB is a full time employee of Novartis UK and does not have shares in the company.

\section{Authors' contributions}

All authors participated in the development of this manuscript. SC, JJ, FB, AE participated in all stages of the study design, systematic literature view, statistical analyses and manuscript development. JD, MK, GC, MB, PJ participated in the study design and coordination and helped to draft the manuscript. All authors read and approved the final manuscript.

\section{Author details}

'MAPI Consultancy, Toronto, Canada. ${ }^{2}$ Department of Medicine, University North Carolina, North Carolina, USA. ${ }^{3}$ MAPI Consultancy, Boston, USA.

${ }^{4}$ Novartis Pharma AG, Basel, Switzerland. ${ }^{5}$ Novartis Horsham Research Centre, Horsham, UK. 'Division of Clinical Science, St George's University of London, London SW17 ORE, UK.

Received: 14 June 2013 Accepted: 25 September 2013

Published: 7 October 2013

\section{References}

1. Global Initiative for Chronic Obstructive Lung Disease (GOLD): global strategy for the diagnosis management and prevention of chronic obstructive pulmonary disease. http//www.goldcopd.org/uploads/users/files/GOLD_Report_2013Feb13.pdf.

2. Jones PW: St. George's Respiratory questionnaire: MCID. COPD 2005, 2:75-79.

3. Witek TJ Jr, Mahler DA: Minimal important difference of the transition dyspnoea index in a multinational clinical trial. Eur Respir J 2003, 21:267-272.

4. Firth R, Henley M, Kramer B, Lassen C, Yang W, Owen R: Full clinical study report for study number QAB149B2333: a phase III, 26-week multi-center randomized double-blind, placebo-controlled, parallel-group study to assess the efficacy, safety and tolerability of indacaterol (150 and $300 \mu \mathrm{g}$ od) in patients with chronic obstructive pulmonary disease. Novartis data on file 2010.

5. Buhl R, Dunn L, Disdier C, Lassen C, Amos C, Henley M, Kramer B: Blinded 12- week comparison of once-daily indacaterol and tiotropium in COPD. Eur Respir J 2011, 38:797-803.

6. Dahl R, Chung KF, Buhl R, Magnussen H, Nonikov V, Jack D, Bleasdale $P$, Owen R, Higgins M, Kramer B: L Efficacy of a new once-daily long-acting inhaled beta2-agonist indacaterol versus twice-daily formoterol in COPD. Thorax 2010, 65:473-479.

7. Donohue JF, Fogarty C, Lötvall J, Mahler DA, Worth H, Yorgancioglu A, Iqbal A, Swales J, Owen R, Higgins M, Kramer B: Once-daily bronchodilators for chronic obstructive pulmonary disease: indacaterol versus tiotropium. Am J Respir Crit Care Med 2010, 182:155-162.

8. D'Urzo A, Ferguson GT, van Noord JA, Hirata K, Martin C, Horton R, Lu Y, Banerji D, Overend T: Efficacy and safety of once-daily NVA237 in patients with moderate to severe COPD: the GLOW1 trial. Respir Res 2011, 12:156.

9. Feldman G, Siler T, Prasad N, Jack D, Piggott S, Owen R, Higgins M, Kramer B: Efficacy and safety of indacaterol 150 microg once-daily in COPD: a double-blind, randomised, 12-week study. BMC Pulm Med 2010, 10:1-9.

10. Kerwin EM, Gotfried MH, Lawrence D, Lassen C, Kramer B: Efficacy and tolerability of indacaterol $75 \mu \mathrm{g}$ once daily in patients aged $\geq 40$ years with chronic obstructive pulmonary disease: results from 2 double-blind, placebo-controlled 12-week studies. Clin Ther 2011, 33:1974-1984.

11. Kerwin E, Hébert J, Gallagher N, Martin C, Overend T, Alagappan VK, Lu Y, Banerji D: Efficacy and safety of NVA237 versus placebo and tiotropium in patients with moderate-to-severe COPD over 52 weeks: The GLOW2 study. Eur Respir J 2012, 40:1106-1114.

12. Kinoshita M, Lee SH, Hang LW, Ichinose M, Hosoe M, Okino N, Prasad N, Kramer B, Fukuchi Y: Efficacy and safety of indacaterol 150 and $300 \mu \mathrm{g}$ in chronic obstructive pulmonary disease patients from six Asian areas including Japan: a 12-week, placebo-controlled study. Respirology 2012, 17:379-389

13. Korn S, Kerwin E, Atis S, Amos C, Owen R, Lassen C: Indacaterol once-daily provides superior efficacy to salmeterol twice-daily in COPD: A 12-week study. Respir Med 2011, 105:719-726.

14. Kornmann O, Dahl R, Centanni S, Dogra A, Owen R, Lassen C, Kramer B: Once-daily indacaterol versus twice-daily salmeterol for COPD: a placebo-controlled comparison. Eur Respir J 2011, 37:273-279. 
15. Caldwell DM, Ades AE, Higgins JP: Simultaneous comparison of multiple treatments: combining direct and indirect evidence. BMJ 2005, 331:897-900.

16. LU G, Ades AE: Combination of direct and indirect evidence in mixed treatment comparisons. Stat Med 2004, 23:3105-3124.

17. Jansen J, Crawford B, Bergman G, Stam W: Bayesian meta-analysis of multiple treatment comparisons: an introduction to mixed treatment comparisons. Value Health 2008, 11:956-964.

18. Jansen JP, Fleurence R, Devine B, Itzler R, Barrett A, Hawkins N, Lee K, Boersma C, Annemans L, Cappelleri JC: Interpreting indirect treatment comparisons and network meta-analysis for health-care decision making: report of the ISPOR task force on indirect treatment comparisons good research practices: part 1. Value Health 2011, 14:417-428.

19. Spiegelhalter D, Abrams K, Myles J: Bayesian approaches to clinical trials and health care evaluation. Chichester, UK: Wiley; 2004.

20. Hoaglin DC, Hawkins N, Jansen JP, Scott DA, Itzler R, Cappelleri JC, Boersma C, Thompson D, Larholt KM, Diaz M, Barrett A: Conducting indirecttreatment-comparison and network-meta-analysis studies: report of the ISPOR task force on indirect treatment comparisons good research practices: part 2. Value Health 2011, 14:429-437.

21. Dias S, Sutton AJ, Ades AE, Welton NJ: A generalized linear modeling framework for pairwise and network meta-analysis of randomized controlled trials. Med Decis Making 2013, 33(5):607-17.

22. Cooper NJ, Sutton AJ, Morris D, Ades AE, Welton NJ: Addressing betweenstudy heterogeneity and inconsistency in mixed treatment comparisons: application to stroke prevention treatments in individuals with nonrheumatic atrial fibrillation. Stat Med 2009, 28:1861-1881.

23. Dempster AP: The direct use of likelihood for significance testing. Stat Comput 1997, 7:247-252.

24. Lunn DJ, Thomas A, Best N, Spiegelhalter D: WinBUGS - a Bayesian modelling framework: concepts, structure, and extensibility. Stat Comput 2000, 10:325-337.

25. Salanti G, Ades AE, loannidis JP: Graphical methods and numerical summaries for presenting results from multiple-treatment meta-analyses: an overview and tutorial. J Clin Epidemiol 2011, 64:163-171.

26. Bateman ED, Tashkin D, Siafakas N, Dahl R, Towse L, Massey D, Pavia D, Zhong NS: A one-year trial of tiotropium Respimat plus usual therapy in COPD patients. Respir Med 2010, 104:1460-1472.

27. Bateman E, Singh D, Smith D, Disse B, Towse L, Massey D, Blatchford J, Pavia D, Hodder R: Efficacy and safety of tiotropium Respimat SMI in COPD in two 1-year randomized studies. Int J Chron Obstruct Pulmon Dis 2010, 5:197-208.

28. Briggs DD Jr, Covelli H, Lapidus R, Bhattycharya S, Kesten S, Cassino C: Improved daytime spirometric efficacy of tiotropium compared with salmeterol in patients with COPD. Pulm Pharmacol Ther 2005, 18:397-404

29. Brusasco V, Hodder R, Miravitlles M, Korducki L, Towse L, Kesten S: Health outcomes following treatment for six months with once daily tiotropium compared with twice daily salmeterol in patients with COPD. Thorax 2003, 58:399-404.

30. Calverley P, Pauwels R, Vestbo J, Jones P, Pride N, Gulsvik A, Anderson J, Maden C: Combined salmeterol and fluticasone in the treatment of chronic obstructive pulmonary disease: a randomised controlled trial. Lancet 2003, 361:449-456.

31. Calverley PM, Anderson JA, Celli B, Ferguson GT, Jenkins C, Jones PW, Yates $J C$, Vestbo J: Salmeterol and fluticasone propionate and survival in chronic obstructive pulmonary disease. N Eng J Med 2007, 356:775-789.

32. Casaburi R, Briggs DD Jr, Donohue JF, Serby CW, Menjoge SS, Witek TJ Jr: The spirometric efficacy of once-daily dosing with tiotropium in stable COPD: A 13-week multicentre trial. Chest 2000, 118:1294-1302.

33. Casaburi R, Mahler DA, Jones PW, Wanner A, San PG, ZuWallack RL, Menjoge SS, Serby CW, Witek T Jr: A long-term evaluation of once-daily inhaled tiotropium in chronic obstructive pulmonary disease. Eur Respir J 2002, 19:217-224.

34. Celli B, Halpin D, Hepburn R, Byrne N, Keating ET, Goldman M: Symptoms are an important outcome in chronic obstructive pulmonary disease clinical trials: results of a 3-month comparative study using the Breathlessness, Cough and Sputum Scale BCSS. Respir Med 2003, 97(Suppl A):S35-S43.

35. Chan CK, Maltais F, Sigouin C, Haddon JM, Ford GT: A randomized controlled trial to assess the efficacy of tiotropium in Canadian patients with chronic obstructive pulmonary disease. Can Respir J 2007, $14: 465-472$.
36. Chapman KR, Arvidsson P, Chuchalin AG, Dhillon DP, Faurschou P, Goldstein RS, Kuipers AF: The addition of salmeterol 50 microg bid to anticholinergic treatment in patients with COPD: A randomized, placebo controlled trial. Chronic obstructive pulmonary disease. Can Respir J 2002, 9:178-185.

37. Covelli H, Bhattacharya S, Cassino C, Conoscenti C, Kesten S: Absence of electrocardiographic findings and improved function with once-daily tiotropium in patients with chronic obstructive pulmonary disease. Pharmacotherapy 2005, 25:1708-1718.

38. Dahl R, Greefhorst LA, Nowak D, Nonikov V, Byrne AM, Thomson MH, Till D, Della Cioppa G: Inhaled formoterol dry powder versus ipratropium bromide in chronic obstructive pulmonary disease. Am J Respir Crit Care Med 2001, 164:778-784.

39. Donohue JF, van Noord JA, Bateman ED, Langley SJ, Lee A, Witek TJ Jr, Kesten S, Towse L: A 6-month, placebo-controlled study comparing lung function and health status changes in COPD patients treated with tiotropium or salmeterol. Chest 2002, 122:47-55.

40. Gross NJ, Nelson HS, Lapidus RJ, Dunn L, Lynn L, Rinehart M, Denis-Mize K, Formoterol study group: Efficacy and safety of formoterol fumarate delivered by nebulization to COPD patients. Respir Med 2008, 102:189-197.

41. Hanania NA, Darken P, Horstman D, Reisner C, Lee B, Davis S, Shah T: The efficacy and safety of fluticasone propionate (250 mug)/salmeterol (50 mug) combined in the Diskus inhaler for the treatment of COPD. Chest 2003, 124:834-843.

42. Jones PW, Rennard SI, Agusti A, Chanez P, Magnussen H, Fabbri L, Donohue J, Bateman ED, Gross NJ, Lamarca R, Caracta C, Garcia Gil E: Efficacy and safety of once-daily aclidinium in chronic obstructive pulmonary disease. Respir Res 2011, 12:55.

43. Mahler DA, Wire P, Horstman D, Chang CN, Yates J, Fischer T, Shah T: Effectiveness of fluticasone propionate and salmeterol combination delivered via the Diskus device in the treatment of chronic obstructive pulmonary disease. Am J Respir Crit Care Med 2002, 166:1084-1091.

44. Moita J, Bárbara C, Cardoso J, Costa R, Sousa M, Ruiz J, Santos ML: Tiotropium improves $\mathrm{FEV}_{1}$ in patients with COPD irrespective of smoking status. Pulm Pharmacol Ther 2008, 21:146-151.

45. Niewoehner DE, Rice K, Cote C, Paulson D, Cooper JA Jr, Korducki L, Cassino C, Kesten S: Prevention of exacerbations of chronic obstructive pulmonary disease with tiotropium, a once-daily inhaled anticholinergic bronchodilator: a randomized trial. Ann Intern Med 2005, 143:317-326.

46. Rossi A, Kristufek P, Levine BE, Thomson MH, Till D, Kottakis J, Della Cioppa G: Comparison of the efficacy, tolerability, and safety of formoterol dry powder and oral, slow-release theophylline in the treatment of COPD. Chest 2002, 121:1058-1069.

47. Rutten-van Mölken M, Roos B, Van Noord JA: An empirical comparison of the St George's Respiratory Questionnaire SGRQ and the Chronic Respiratory Disease Questionnaire CRQ in a clinical trial setting. Thorax 1999, 54:995-1003.

48. Tashkin DP, Celli B, Senn S, Burkhart D, Kesten S, Menjoge S, Decramer M: A 4-year trial of tiotropium in chronic obstructive pulmonary disease. N Engl J Med 2008, 359:1543-1554.

49. Tonnel AB, Perez T, Grosbois JM, Verkindre C, Bravo ML, Brun M: Effect of tiotropium on health-related quality of life as a primary efficacy endpoint in COPD. Int J Chron Obstruct Pulmon Dis 2008, 3:301-310.

50. Verkindre C, Bart F, Aguilaniu B, Fortin F, Guérin JC, Le Merre C, lacono P, Huchon G: The effect of tiotropium on hyperinflation and exercise capacity in chronic obstructive pulmonary disease. Respiration 2006, 73:420-427.

51. Vogelmeier C, Kardos P, Harari S, Gans SJ, Stenglein S, Thirlwell J: Formoterol mono- and combination therapy with tiotropium in patients with COPD: a 6-month study. Respir Med 2008, 102:1511-1520.

52. Voshaar T, Lapidus R, Maleki-Yazdi R, Timmer W, Rubin E, Lowe L, Bateman E: A randomized study of tiotropium Respimat Soft Mist Inhaler vs. ipratropium pMDI in COPD. Respir Med 2008, 102:32-341.

53. Boyd G, Morice AH, Pounsford JC, Siebert M, Peslis N, Crawford C: An evaluation of salmeterol in the treatment of chronic obstructive pulmonary disease COPD. Eur Respir J 1997, 10:815-821.

54. Campbell SC, Criner GJ, Levine BE, Simon SJ, Smith JS, Orevillo CJ, Ziehmer BA: Cardiac safety of formoterol 12 microg twice daily in patients with chronic obstructive pulmonary disease. Pulm Pharmacol Ther 2007, 20:571-579.

55. Criner GJ, Sharafkhaneh A, Player R, Conoscenti CS, Johnson P, Keyser MT, Cassino C: Efficacy of tiotropium inhalation powder in african-american 
patients with chronic obstructive pulmonary disease. COPD 2008, 5:35-41.

56. Dusser D, Bravo ML, lacono P: The effect of tiotropium on exacerbations and airflow in patients with COPD. Eur Respir J 2006, 27(3):547-555.

57. Freeman D, Lee A, Price D: Efficacy and safety of tiotropium in COPD patients in primary care--the SPiRiva Usual CarE (SPRUCE) study. Respir Res 2007, 8:45. epub.

58. Jones PW, Bosh TK: Quality of life changes in COPD patients treated with salmeterol. Am J Respir Crit Care Med 1997, 155:1283-1289.

59. O'Donnell DE, Sciurba F, Celli B, Mahler DA, Webb KA, Kalberg CJ, Knobil K: Effect of fluticasone propionate/salmeterol on lung hyperinflation and exercise endurance in COPD. Chest 2006, 130:647-656.

60. Powrie DJ, Wilkinson TM, Donaldson GC, Jones P, Scrine K, Viel K, Kesten S, Wedzicha JA: Effect of tiotropium on sputum and serum inflammatory markers and exacerbations in COPD. Eur Respir J 2007, 30:472-478.

61. Stockley RA, Chopra N, Rice L: Addition of salmeterol to existing treatment in patients with COPD: a 12 month study. Thorax 2006, 6:122-128.

62. van Noord JA, de Munck DR, Bantje TA, Hop WC, Akveld ML, Bommer AM: Long-term treatment of chronic obstructive pulmonary disease with salmeterol and the additive effect of ipratropium. Eur Respir J 2000, 15:878-885.

63. Vogelmeier C, Hederer B, Glaab T, Schmidt H, Rutten-van Mölken MP, Beeh KM, Rabe KF, Fabbri LM: Tiotropium versus salmeterol for the prevention of exacerbations of COPD. N Engl J Med 2011, 364:1093-1103.

64. Baker WL, Baker EL, Coleman Cl: Pharmacologic treatments for chronic obstructive pulmonary disease: a mixed-treatment comparison metaanalysis. Pharmacotherapy 2009, 29:891-905

65. Cazzola M, MacNee W, Martinez FJ, Rabe KF, Franciosi LG, Barnes PJ, Brusasco V, Burge PS, Calverley PMA, Celli BR, Jones PW, Mahler DA, Make B, Miravitlles M, Page CP, Palange P, Parr D, Pistolesi M, Rennard SI, Rutten-van Mölken MP, Stockley R, Sullivan SD, Wedzicha JA, Wouters EF: Outcomes for COPD pharmacological trials: from lung function to biomarkers. Eur Respir J 2008, 31:416-469.

66. Donohue JF, Singh D, Kornmann O, Lawrence D, Lassen C, Kramer B: Safety of indacaterol in the treatment of patients with COPD. Int J Chron Obstruct Pulmon Dis 2011, 6:477-492.

67. Qaseem A, Wilt TJ, Weinberger SE, Hanania NA, Criner G, van der Molen T, Marciniuk DD, Denberg T, Schünemann H, Wedzicha W, MacDonald R, Shekelle P: Diagnosis and management of stable chronic obstructive pulmonary disease: a clinical practice guideline update from the American College of Physicians, American College of Chest Physicians, American Thoracic Society, and European Respiratory Society. Ann Intern Med 2011, 155:179-191.

68. Beeh K, Beier J, Donohue JF: Clinical trial design in chronic obstructive pulmonary disease: current perspectives and considerations with regard to blinding of tiotropium. Respir Res 2012, 13:52.

69. Maltais F, Celli B, Casaburi R, Porszasz J, Jarreta D, Seoane B, Caracta C: Aclidinium bromide improves exercise endurance and lung hyperinflation in patients with moderate to severe COPD. Respir Med 2011, 105:580-587.

70. Jones PW, Singh D, Bateman ED, Agusti A, Lamarca R, de Miquel G, Segarra R, Caracta C, Gil EG: Efficacy and safety of twice-daily aclidinium bromide in COPD patients: the ATTAIN study. Eur Respir J 2012, 40:830-836.

71. Puhan MA, Bachmann LM, Kleijnen J, Ter Riet G, Kessels AG: Inhaled drugs to reduce exacerbations in patients with chronic obstructive pulmonary disease: a network meta-analysis. BMC Med 2009, 7:2.

72. Cope S, Capkun-Niggli G, Gale R, Jardim JR, Jansen JP: Comparative efficacy of indacaterol $150 \mu \mathrm{g}$ and $300 \mu \mathrm{g}$ versus fixed-dose combinations of formoterol + budesonide or salmeterol + fluticasone for the treatment of chronic obstructive pulmonary disease-a network meta-analysis. Int J Chron Obstruct Pulmon Dis 2011, 6:329-344.

73. Cope S, Kraemer M, Zhang J, Capkun-Niggli G, Jansen JP: Efficacy of indacaterol $75 \mu \mathrm{g}$ versus fixed-dose combinations of formoterol/ budesonide or salmeterol/fluticasone for COPD - a network metaanalysis. Int J Chron Obstruct Pulmon Dis 2012, 7:415-420.

74. Cope S, Capkun-Niggli G, Gale R, Lassen C, Owen R, Ouwens MJ, Bergman $G$, Jansen JP: Efficacy of Once-daily indacaterol relative to alternative bronchodilators in COPD: a patient level mixed treatment comparison. Value Health 2012, 15:524-533.
75. Cope S, Zhang J, Williams J, Jansen JP: Efficacy of once-daily indacaterol $75 \mu \mathrm{g}$ relative to alternative bronchodilators in COPD: A study level and a patient level network meta-analysis. BMC Pulm Med 2012, 12:29.

76. Chong J, Karner C, Poole P: Tiotropium versus long-acting beta-agonists for stable chronic obstructive pulmonary disease. Cochrane Database Syst Rev 2012, 9, CD009157.

77. Rodrigo GJ, Neffen $\mathrm{H}$ : Comparison of indacaterol with tiotropium or twice-daily long-acting $\beta$-agonists for stable COPD: a systematic review. Chest 2012, 142:1104-1110.

78. Karner C, Chong J, Poole P: Tiotropium versus placebo for chronic obstructive pulmonary disease. Cochrane Database Syst Rev 2012, 7, CD009285.

79. Calverley PM, Anderson JA, Celli B, Ferguson GT, Jenkins C, Jones PW, Crim C, Willits LR, Yates JC, Vestbo J: Cardiovascular events in patients with COPD: TORCH study results. Thorax 2010, 65:719-725.

80. Kliber A, Lynd LD, Sin DD: The effects of long-acting bronchodilators on total mortality in patients with stable chronic obstructive pulmonary disease. Respir Res 2010, 11:56.

81. Rodrigo GJ, Nannini LJ, Rodríguez-Roisin R: Safety of long-acting betaagonists in stable COPD: a systematic review. Chest 2008, 133:1079-1087.

82. Singh S, Loke YK, Enright PL, Furberg CD: Mortality associated with tiotropium mist inhaler in patients with chronic obstructive pulmonary disease: systematic review and meta-analysis of randomised controlled trials. BMJ 2011, 342:d3215.

83. Worth $\mathrm{H}$, Chung KF, Felser JM, Hu H, Rueegg P: Cardio- and cerebrovascular safety of indacaterol vs formoterol, salmeterol, tiotropium and placebo in COPD. Respir Med 2011, 105:571-579.

doi:10.1186/1465-9921-14-100

Cite this article as: Cope et al.: Comparative efficacy of long-acting bronchodilators for COPD - a network meta-analysis. Respiratory Research $201314: 100$

\section{Submit your next manuscript to BioMed Central and take full advantage of:}

- Convenient online submission

- Thorough peer review

- No space constraints or color figure charges

- Immediate publication on acceptance

- Inclusion in PubMed, CAS, Scopus and Google Scholar

- Research which is freely available for redistribution 